\title{
Quantifier Words And Their Multi-functional(?) Parts"
}

\author{
Anna Szabolcsi, James Doh Whang, and Vera Zu \\ New York University \\ March 11, 2013
}

\begin{abstract}
Formal semantic analyses often take words to be minimal building blocks for the purposes of compositionality. But various recent theories of morphology and syntax have converged on the view that there is no demarcation line corresponding to the word level. The same conclusion has emerged from the compositional semantics of superlatives. In the spirit of extending compositionality below the word level, this paper explores how a small set of particles (Japanese $\mathrm{ka}$ and $m o$, Chinese dou, and Hungarian vala/vagy, mind, and is) form quantifier words and serve as connectives, additive and scalar particles, question markers, and existential verbs. Our main question is whether the meanings of these particles across the varied environments are highly regular, or they are lexicalized with a variety of different meanings that bear a family resemblance. This paper does not reach definitive conclusions, but it raises analytical possibilities using Boolean semantics and Inquisitive Semantics (the semantics of alternatives). It also draws attention to systematic similarities and some differences between the multiple uses of $m o$ and $d o u$ that have not been studied in the literature, and reviews accounts in terms of maximality and additivity.
\end{abstract}

Keywords: quantificational particle, indeterminate pronoun, Boolean, Inquisitive, maximality, additive, typology, semantics, syntax, morphology

\section{Compositionality}

Research in semantics is guided by the principle of compositionality.

(1) The meaning of a complex expression is a function of the meanings of its parts and how they are put together.

What are the "parts" that the principle refers to? This question has been phrased in many ways and answered in many ways, depending on the semanticist's views on the theory of grammar. Are the relevant parts surface constituents? LF con-

\footnotetext{
* A preliminary version of this paper was presented at the Workhop on Syntax/semantics Interface, Academia Sinica, 2011. We are grateful to that audience and to the anonymous reviewers of this paper for comments, and to Dylan Bumford for his contribution to our thinking about the Japanese/Chinese comparison. Final version to appear in Language and Linguistics 15/1, http://www.ling.sinica.edu.tw/publ i en.asp.htm.
} 
stituents? Only audible parts? Possibly also phonetically empty ones? How do type-shifting and coercion fit into the picture? This paper proposes yet another way of asking the question.

(2) Are (phonological) words the smallest parts that a compositional grammar should take into account? If not, what smaller parts are to be recognized?

Although there is no doctrine that says that word meanings are the minimal building blocks of sentence meanings, in practice semanticists often make that assumption. For example, we readily assign very complex interpretations to quantificational words without specifying how the semantic ingredients are anchored in the components of those words. That practice is probably motivated by the time-honored lexicalist tradition in syntax. It is therefore of some interest to observe that in the past two decades different lines of research have been converging on the view that words do not have a distinguished status in morphosyntax. If that is on the right track, then it does not go without saying that words are minimal building blocks for compositional semantics.

Section 2 of the paper briefly recapitulates some results pertaining to the continuity of morphology/lexicon, syntax, and semantics. Expanding upon Szabolcsi (2010: Ch. 12), Sections 3 through 6 draw attention to a domain of data in which recognizing the components of quantifier words seems especially interesting from a semantic point of view. Focusing on Japanese, Chinese, and Hungarian we examine how a small set of operator particles (Japanese $k a$ and $m o$, Chinese $d o u$, and their Hungarian counterparts) form quantifier words and serve as connectives, additive and scalar particles, question markers, and existential verbs. The main point we wish to make is that if semanticists are willing to abandon the safety of word boundaries, and ask how the individual morphemes contribute to the complex meanings of quantifier words, they are likely to find some robust regularities and new insights. Cross-linguistic comparisons are especially rewarding. It is often difficult to determine, within one language, whether two particles are just homonyms or really the same thing, and whether a set of semantic functions form a natural class. The recurrence of patterns across languages is of great help, much like it is in other areas of grammar.

The ultimate question is whether the meanings of these particles across the varied environments are highly regular, or they are lexicalized with a variety of different meanings that bear a family resemblance. This is a big question, and the present paper cannot reach a definitive conclusion. It makes the first steps towards finding the answers by (i) presenting the cross-linguistic data in a way that is conducive to asking our new questions, and (ii) by exploring some unifying perspectives. These are Boolean semantics (possibly for all the particles), Inquisitive Semantics (as of date, primarily for what we will call members of the " $k a$ - 
family"), and proposals building on maximality and the additive function (as of date, primarily for members of the " $m o / d o u$-family").

\section{Lessons from Distributed Morphology, Minimalist Syntax, and formal semantics}

Section 2 reviews theories in morphology, syntax, and semantics that converge on abandoning words as building blocks. It proposes that the next task is to find out whether uniform interpretations can be assigned to the constituent morphemes across the various environments in which they occur.

\subsection{Distributed Morphology}

Two of the assumptions of Distributed Morphology (Halle \& Marantz 1994) that are especially relevant to us are "Hierarchical syntactic structure all the way down" and "Late insertion of vocabulary items". DM builds syntactic structures of the usual sort out of morpho-syntactic features of two types, 1-morphemes (roots) and f-morphemes (e.g. plural, past). DM does not build sentences out of traditional lexical items like destroy (which has a causative meaning without overt causative morphology), weaken (causative meaning with causative morphology), sleeping (with regular inflection), or even slept (with somewhat irregular inflection). Lexical items in the traditional sense do not even exist in the theory. Once syntactic structure is built out of roots and abstract features, it is input to logical form operations, and to morphological and phonological operations, among others the insertion of phonological expressions dubbed vocabulary items. Logical Form, Phonological Form, and the Encyclopedia each feed the meaning of the sentence on their own. Given these assumptions, the typological differences between polysynthetic and isolating languages do not require the postulation of radically different combinatoric and compositional mechanisms in UG, and the phonological word has no special status in semantic interpretation. See Harley (2012) for detailed discussion of semantic interpretation in DM.

The diagram below summarizes Harley's discussion of an extremely simple example, John slept. It illustrates that even in the presence of a verb that has a special allomorph in the context of PAST, DM keeps the verb root and the inflectional morpheme separate in the syntactic derivation, and allows each to contribute to interpretation where it belongs. 
(3)

Linearization, Morphological Merger, Late Insertion, Phonological constraints

$\mathrm{SLEEP} \Leftrightarrow / \mathrm{slEp} /\left[[\mathrm{PAST}]_{\mathrm{T}} \_\right]$

$\mathrm{PAST} \Leftrightarrow / \mathrm{d} /$

$\left.\left[[/ \mathrm{dZAn} /]_{\mathrm{DP}}[/ \mathrm{slEpd} /]_{\mathrm{VP}}\right]_{\mathrm{TP}}\right]$

$[>$ dZAn $>>$ slEpt]

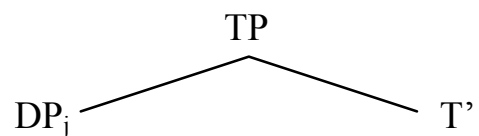

I

$\mathrm{D}$

$\mathrm{JOHN}_{+\mathrm{Nom}}$

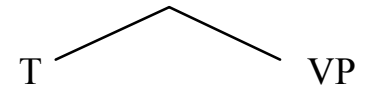

$\mathrm{PAST}_{+\mathrm{Nom}}$

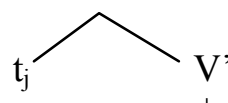

$\mathrm{V}$

SLEEP

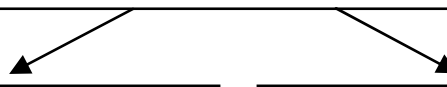

LF Interpretation

VP: ii[ $[$ e $[\operatorname{SLEEP}(\mathrm{e}, \mathrm{John}) \&$ DURING(e,i)]]

TP: BEFORE(utt-time, ti $[\exists e[\operatorname{SLEEP}(e, J o h n) \&$ DURING(e,i)]])

\subsection{Minimalist Syntax}

Some versions of Minimalist Syntax make assumptions that are rather similar in spirit to those of Distributed Morphology (see Julien 2002; Kayne 2005, 2010; Koopman 2005; Koopman \& Szabolcsi 2000; Sigurðsson 2004; Starke 2009; and many others). One of these assumptions is that each syntactic head carries one and only one feature. It follows that phonological words correspond to potentially large chunks of syntactic structure. Especially when remnant movement is allowed, many words will not even correspond to complex heads assembled by head movement in syntax, because at least some of the building blocks are phrases.

For illustration let us consider the recent analysis of jede Frau 'every woman' in Leu (2010), which builds on a theory of the internal structure of German adjectival phrases and determiners developed in Leu (2009). The semantic core of the phrase is formed by the distributive morpheme je and the NP Frau, which correspond to the traditionally recognized constituents of English every woman. In contrast to every, jede also contains $-d$ and the agreement morpheme $-e$. One 
might assume that $-d$ is the definite article, but that would predict that the choice of the agreement morphemes matches article agreement. Leu observes that, instead, it matches adjectival agreement. He argues that the $-d$ in jede is the relative pronoun.

$$
\begin{aligned}
& \text { je-d-er Mann 'every man’ } \\
& \text { je-d-e Frau 'every woman' } \\
& \text { je-d-es Kind 'every child' }
\end{aligned}
$$
gut-er Mann 'good man'
vs. d-er Mann 'the man'
gut-e Frau 'good woman'
vs. d-ie Frau 'the woman'
gut-es Kind 'good child'
vs. d-as Kind 'the child'

Therefore, the NP Frau must enter into a canonical specifier-head configuration with the Adjectival Agreement (AgrA) head. The sequence that is spelled out as jede Frau is a result of four phrasal movement steps, displayed in (5).

First, the NP Frau moves from je-P to the specifier of AgrA; second, the remnant je-P moves to a position above the relative D; third, the NP Frau moves out the phrase so formed, which Leu considers an adjectival projection XAP; lastly, a phonetically silent determiner $\mathrm{D}^{*}$ is merged, and the remnant xAP jede moves to its specifier. The phonological word jede is dominated by a single XAP node, but xAP does not exclusively dominate jede in the course of the derivation, and jede could not be assembled purely by a sequence of head movements.

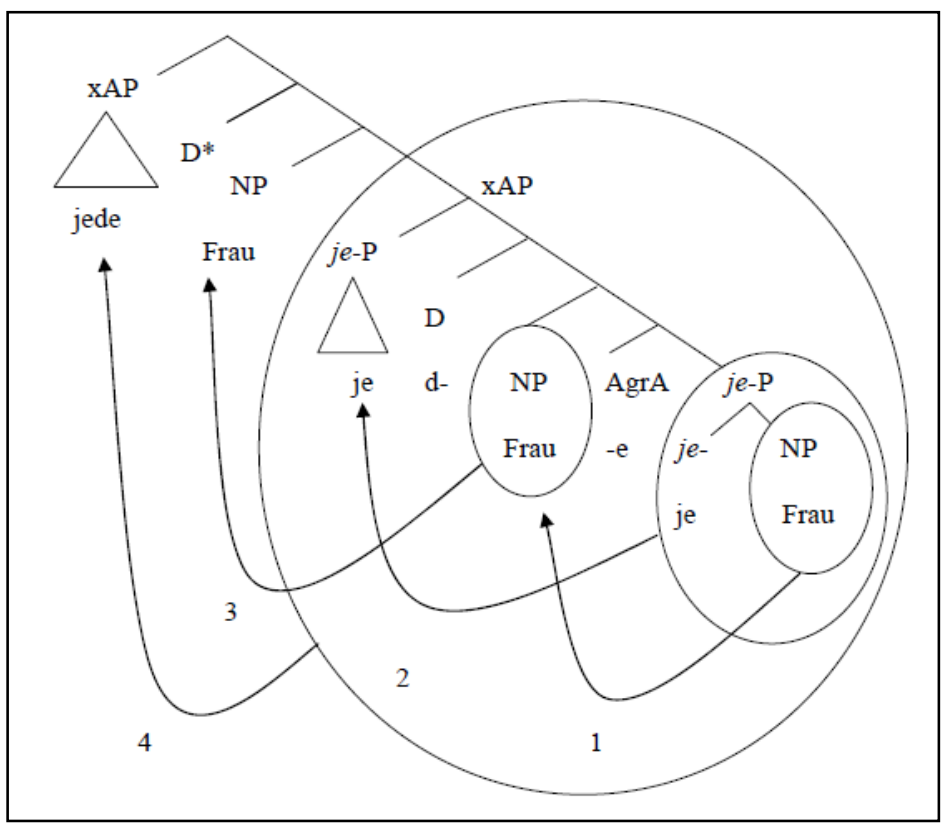


In this example the movements involving je and Frau are syntactically motivated; the semantically significant constellation is the initial one, where the two form je-P. It is important to point out that remnant movement reconstructs, because the remnant contains a trace that needs to be bound by its antecedent. Therefore the movements listed above do not alter interpretation.

\subsection{The semantics of superlatives}

The determiner most is perhaps the best-explored example of a quantifier word that needs to be composed from smaller parts and whose smaller parts also reach beyond its boundaries, in order to obtain the correct interpretations in a compositional manner. As was observed in Heim (1985) and Szabolcsi (1986), sentences with superlative adjectives exhibit an ambiguity:

Who climbed the highest mountain?

(a) Absolute: Who climbed the highest among mountains?

(b) Relative: Who climbed a higher mountain than how high a mountain anyone else climbed?

Both Heim (1985) and Szabolcsi (1986) described the ambiguity in terms of the scope of the superlative morpheme. On the absolute reading the scope of -est is DP-internal: the definition of the comparison class involves only DP-internal material. The highest mountain is understood to be the highest among mountains. On the relative reading -est takes sentence-level scope: the comparison involves who climbed what mountains. The syntax and semantics of comparatives and superlatives was the first domain where a part of a word was assumed to take scope over a larger chunk of the sentence, defying word boundaries - in this case, at LF.

Hackl (2009) represents the two readings as follows, adopting Heim's (1985, 1999) semantics. The variable $C$ introduces a contextually relevant set of entities; mountains in (a), climbers in (b). max picks the maximal degree $d$ in the set defined in $\{d: \ldots d \ldots\}$.

(7) Interpretation of NP-adjunction of [-est C]:

$\left[[\text { [-est C }]_{\mathrm{i}} \quad\left[\mathrm{d}_{\mathrm{i}}\right.\right.$-high mountain] ]] $=\lambda \mathrm{x} . \forall \mathrm{y} \in \mathrm{C}[\mathrm{y} \neq \mathrm{x} \rightarrow$ $\max \{\mathrm{d}: \mathrm{x}$ is a d-high $\operatorname{mnt}\}>\max \{\mathrm{d}: \mathrm{y}$ is a d-high $\mathrm{mnt}\}]$

Interpretation of VP-adjunction of [-est C]:

$\left[[\text { [-est C }]_{\mathrm{i}}\right.$ climbed $\left[\mathrm{d}_{\mathrm{i}}\right.$-high mountain] $\left.]\right]=\lambda \mathrm{x} . \forall \mathrm{y} \in \mathrm{C}[\mathrm{y} \neq \mathrm{x} \rightarrow$ $\max \{\mathrm{d}: \mathrm{x}$ climbed a d-high $\operatorname{mnt}\}>\max \{\mathrm{d}: \mathrm{y}$ climbed a d-high $\operatorname{mnt}\}]$ 
(9)

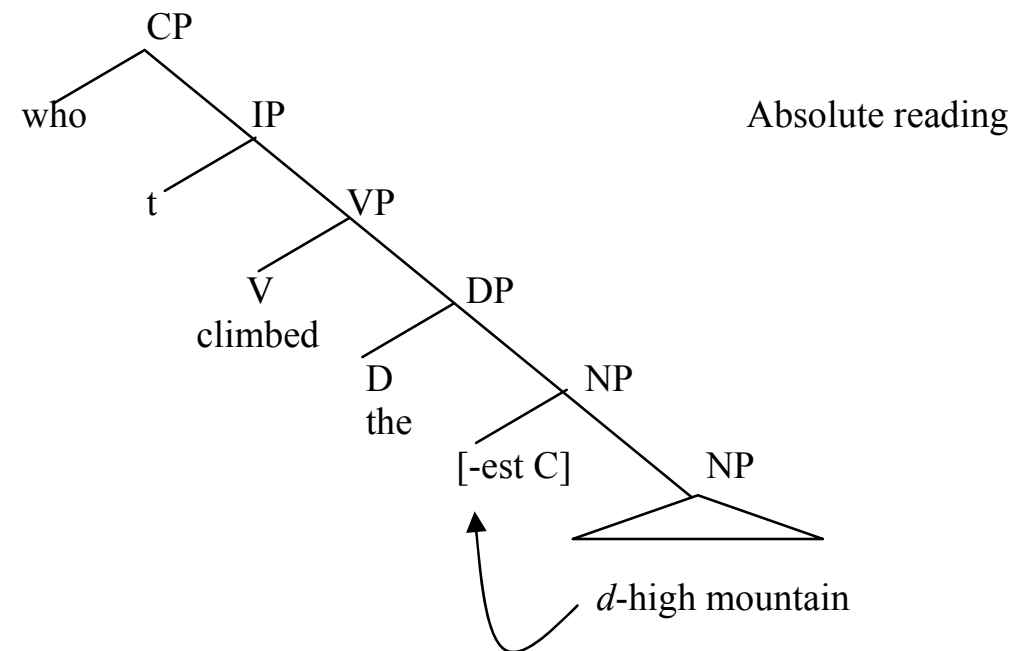

(10)

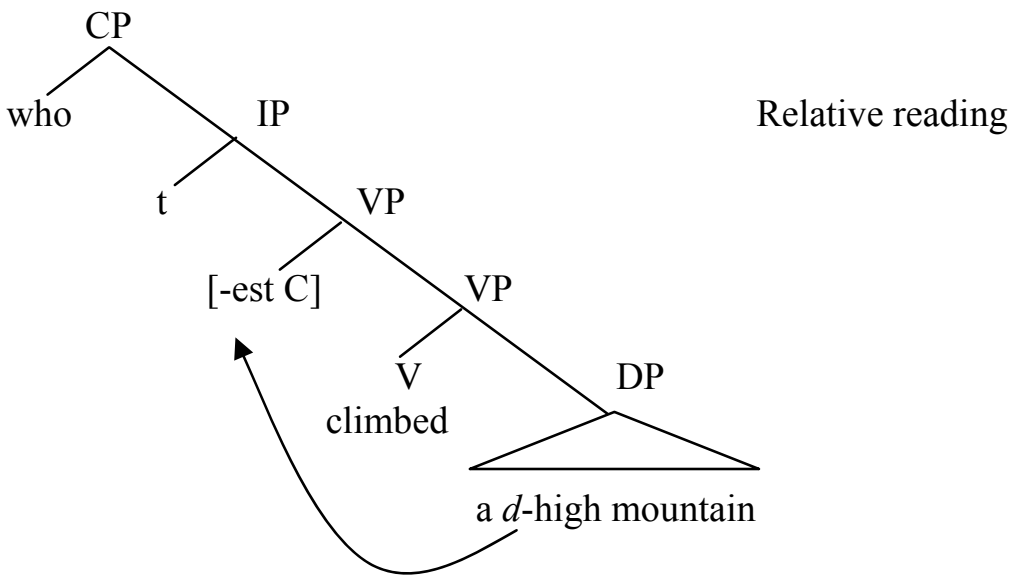

Amount superlatives exhibit a similar absolute/relative contrast. In English the two readings correspond to two slightly different constructions, most (of the) and the most, but other languages, German and Hungarian among them, have a single, ambiguous expression that completely parallels adjectival superlatives.

$\begin{array}{llllll}\mathrm{Ki} & \text { mászta meg a legtöbb } & \text { hegyet? } & \text { Hungarian } \\ \text { who climbed } & \text { prt the most } & \text { mountain-acc } & \end{array}$

i. Absolute reading: Who climbed most (of the) mountains?

'Who climbed a set of mountains whose cardinality was greater than the cardinality of any competing set of mountains?' = 'Who climbed a majority of the mountains?' 
ii. Relative reading: Who climbed the most mountains?

'Who climbed more mountains than how many mountains anyone else climbed?'

The two readings of the amount superlative can be derived and interpreted in analogy to those of the adjectival superlative, replacing $d$-high with $d$-many (cf. how many).

Hackl (2009) argues that accounting for most in this way has conceptual and empirical advantages. The traditional treatment of the proportional determiner most (e.g. in Barwise \& Cooper 1981) takes most to be a primitive. It does not recognize the fact that most is to more as highest is to higher, and an interpretation is assigned to most by a lexical stipulation. Hackl shows that proportional most is nothing other than the absolute reading of superlative most, in terms of both distribution and truth-conditional contribution. His approach furthermore offers an account of the fact that fewest and its cross-linguistic counterparts only support a relative reading.
a. *Who climbed fewest (of the) mountains?
(absolute)
b. Who climbed the fewest mountains?
(relative)

Hackl observes that the compositional semantics that he proposes for the absolute reading of most simply does not yield a viable result when applied to the decreasing counterpart, although it works fine for relative the fewest. (For the details we refer the reader to his article.) This predicts the contrast in $(12 \mathrm{a}, \mathrm{b})$. If both most and fewest were lexical primitives, and their interpretations were not derived compositionally, one could not even begin to ask why fewest (of the) is left without a meaning - for example, why it does not mean 'a minority of the [NPs]'.

As a matter of fact, Bobaljik (2012) observes that evidence from suppletion suggests that Hackl (2009) does not decompose most as much as needed. Crosslinguistically, positive, comparative, and superlative forms exhibit just two, rather than four, suppletive patterns:

$\begin{array}{llllll}\text { a. } & \text { ABC } & \text { bonus } & \text { melior } & \text { optimus } & \text { Latin } \\ \text { b. } & \text { ABB } & \text { good } & \text { better } & \text { best } & \\ \text { c. unattested } & \text { ABA } & \text { good } & \text { better } & \text { goodest } & \\ \text { d. unattested } & \text { AAB } & \text { good } & \text { gooder } & \text { best } & \end{array}$

Bobaljik proposes that fundamental assumptions of Distributed Morphology account for these data if superlatives are not formed directly from the positive base but, instead, properly contain the comparative. Now notice that comparative 
more and superlative most also represent the ABB pattern, whatever we take the positive form (d-many) to be. So, most needs to be broken down even more; but none of the general conclusions are threatened. Importantly, suppletion provides more evidence for "syntactic structure all the way down," and does not point to a need to return to a lexicalist position. For analyses of absolute and relative most in this spirit, see Szabolcsi (2012).

In sum, the case of most illustrates beautifully how useful it is to build a word from smaller parts using regular syntax and a matching compositional semantics, and to allow those parts to reach out to the higher regions of syntactic structure, as well. In other words, it illustrates how irrelevant the wordhood of most is.

\subsection{Interim summary and the next task}

In each of the three cases reviewed above, it was important to build word meanings from constituent parts and to allow those parts to interact with each other and with the rest of the sentence. In the case of the English past tense, the tense morpheme conditions the choice of the verbal allomorph, but it scopes over VP. In the case of German universals, $j e$ combines with $-d$ and adjectival agreement to yield jede, but jede Frau 'every woman' is interpreted based on [je Frau]. Finally, in the case of superlatives, recognizing the relationship between the absolute and relative readings, obtaining the readings themselves, and accounting for the cross-linguistic patterns of suppletion, all require decomposing most and fewest and allowing their operator parts to scope out to the DP or the sentential level. ${ }^{1}$ In short,

(14) Words are not distinguished building blocks in syntax or morphology.

(15) Words are not distinguished building blocks for compositional semantics.

With these conclusions in mind, we turn to a new domain of data that allows us to explore further aspects of how compositional analysis can, and should, extend below the word level in quantificational expressions.

Suppose we have three quantifier words that are clearly bimorphemic: $\mathrm{M}_{1}+\mathrm{M}_{2}, \mathrm{M}_{1}+\mathrm{M}_{3}, \mathrm{M}_{4}+\mathrm{M}_{2}$. We build the meanings of the three words from meanings that we attribute to the four constituent morphemes, based on their contributions to these words. Is that sufficient for making the analysis compositional?

\footnotetext{
${ }^{1}$ The question whether scope assignment is implemented using movement is orthogonal to present concerns, and the decision may vary from theory to theory. The important point is that empirical generalizations do not force us to recognize words as distinguished building blocks outside phonology. With an appropriate logical apparatus it is possible to assign correct interpretations to surface constituents, phonological words among them (cf. Jacobson's 2002 notion of direct compositionality).
} 
If the four morphemes only occur in these words and perhaps a few others that come from the same mold, then the answer may be yes. If however these morphemes also occur in very different further environments, then only paying attention to our initial little paradigm will not do. We need to assign interpretations to $\mathrm{M}_{1}, \mathrm{M}_{2}, \mathrm{M}_{3}$, and $\mathrm{M}_{4}$ in a way that is valid for their occurrences in other environments as well - in all environments that reliably contain the same morphemes.

Such requirement is commonplace in the compositional semantics of phrases. The same standards should apply to compositional semantics involving parts of words. But now the task is more difficult, in part because we semanticists have much less experience with it. It may be difficult to ascertain that the identical, or similar, elements actually represent the same morpheme, and it may be difficult to find the fairly abstract common semantic core. It is tempting to give up and assume that morpheme combinations are lexicalized with particular meanings that cannot be obtained compositionally, or that the morphemes themselves are "multi-functional". In this situation it is very useful to look for a domain of data where similar patterns can be observed in many languages, related and unrelated ones. If the recurrence of the same morpheme in a set of roles is crosslinguistically fairly stable, that indicates that we are not dealing with homonymy in the individual languages. Sub-patterns are probably also suggestive in connection with which of the roles are more closely related and which others may be derived, perhaps with the help of type-shifters or phonetically null morphemes.

Quantifier words of the 'someone' / 'everyone' type and the occurrences of their constituent parts in other environments offer a rich domain of crosslinguistic data for such study. This paper cannot hope to propose a definitive analysis for them. Its goal is,

a. To provide an initial description of the data,

b. To address some concerns, voiced in the typological literature, regarding the cross-linguistics significance of the patterns,

c. To suggest some unifying semantic perspectives, and

d. To indicate some of the currently problematic points and open questions.

In other words, the aim of this paper is to initiate and inspire a systematic study of quantifier words and their constituent parts, rather than to complete the project in one fell swoop. 


\section{Quantifier words and their multi-functional(?) parts}

Section 3 surveys the basic patterns pertaining to quantifier words composed of indeterminate pronouns and quantificational particles. In some languages the same particles also occur in other environments; the section argues that the patterns are cross-linguistically significant and deserve to be examined. In particular, Japanese $k a, m o$, and their Hungarian counterparts are compared.

\subsection{The basic patterns}

3.1.1 Many languages systematically compose their quantifier words from a set of particles and a set of bases, the latter often called indeterminate pronouns. Slavic languages are perhaps the best known for this. Below we provide a small sample from Hungarian, a language that belongs to the Finno-Ugric branch of the Uralic family. A description of Hungarian quantifiers can be found in Csirmaz \& Szabolcsi (2012), with many full-sentential examples. For a general discussion of Hungarian syntax and the syntax/semantics interface, the reader is referred to Kiss (2002). ${ }^{2,3}$

$$
\begin{array}{llllll}
\text { ki } & \text { vala-ki } & \text { minden-ki } & \text { bár-ki } & \text { akár-ki } & \text { sen-ki } \\
\text { PERSON } & \text { some-PRSN } & \text { every-PRSN } & \text { [may]-PRSN } & \text { [want]-PRSN } & \text { [even]-PRSN } \\
\text { 'who' } & \text { 'someone' } & \text { 'everyone' 'anyone' } & \text { 'anyone' } & \text { 'no one' } \\
\text { hol } & \text { vala-hol } & \text { minden-hol } & \text { bár-hol } & \text { akár-hol } & \text { se-hol } \\
\text { PLACE } & \text { some-PLCE } & \text { every-PLCE } & \text { [may]-PLCE } & \text { [want]-PLCE } & \text { [even]-PLCE } \\
\text { 'where' 'somewhere' 'everywhere' 'anywhere' 'anywhere' } & \text { 'nowhere' }
\end{array}
$$

Following Hamblin (1973) the bases are thought to be predicates or sorted variables. E.g. $k i$ and who will be interpreted as $\{\mathrm{x}: \operatorname{PERSON}(\mathrm{x})\}$ or $\mathrm{x}_{\mathrm{PERSON}}$. On either analysis they contribute sets of alternatives of a grammaticized kind to the sentence. They are not thought to have an inherent interrogative force, despite the fact that in their bare form they function as "question words".

${ }^{2}$ Square bracketed [may], [want], and [even] indicate etymologies; see the translations in single quotes for approximate meanings. Bár is a concessive or optative complementizer (Bár esik 'Although it rains,' Bár(csak) esne 'If only it rained'). $S e(n / m)$ is a negative concord (NC) marker that also surfaces as the NC counterpart of 'also' and 'even' ((még) Kati se(m) 'nor Kate, not even Kate'). Etymologically $\mathrm{se}(\mathrm{n} / \mathrm{m})$ is thought to be a combination of is and nem 'not'.

${ }^{3} \mathrm{Hol}$ and where are not mono-morphemic, but this set of examples makes the correspondences easier to illustrate with English glosses and translations. Ho- $l$ consists of an indeterminate pronoun base and an archaic locative suffix, cf. also ho-va 'where to' and ho-nn-an 'where from'. 
What does recent literature say about the quantificational particles that participate in such quantifier words? This paper will only be concerned with the equivalents of vala- 'some' and mind- 'every', so we focus on these below.

Reinhart (1997) proposed to account for the island-free scope of indefinites in English by postulating that they contain a choice-function variable, bound by freely available existential closure. This variable has the same semantic type as determiners, but Reinhart did not consider some and $a(n)$ as its lexical realizations; she considered some and $a(n)$ meaningless. Yatsushiro (2009) proposes that $k a$, the Japanese counterpart of vala and some in indefinites, is a choicefunction variable, bound by existential closure.

Among the quantificational elements, every, minden and their cross-linguistic counterparts, such as Chinese dou and Japanese mo, have received particular attention in the theoretical literature. Beghelli \& Stowell (1997), Szabolcsi (1997a), Lin (1998), and Kratzer \& Shimoyama (2002) all arrived at the conclusion that distributivity is the contribution of a sentence-level functional head, not of the DP-internal determiner. Following Beghelli \& Stowell, this functional head is often referred to as Dist, and dou, mo, or some phonetically null element as the lexical content of Dist. On this view, DP-internal every, minden, and mei signal association with the sentence-level Dist operator and are not distributive operators themselves.

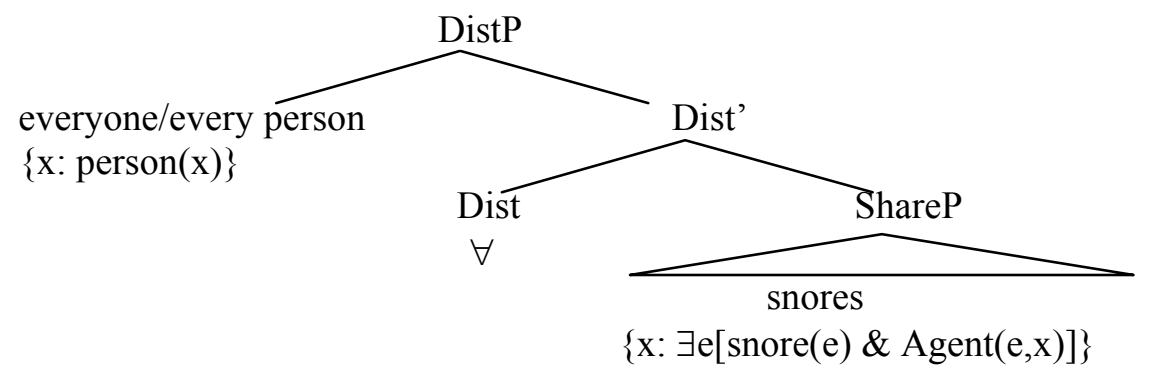

The relationship between every/minden and Dist is likened to that between negative-concord markers and sentence-level negation. Negative-concord markers signal the association, rather than express negation themselves. See Szabolcsi (2010: Ch. 8) for more detailed discussion.

3.1.2 But the particles themselves are not confined to the above quantifier words or contexts. Japanese presents especially extensive paradigms (Nishigauchi 1990; 
Shimoyama 2006, Kobuchi-Philip 2009, and others). The list of functions below is probably incomplete. ${ }^{4}$
a. dare-ka
'someone'
b. gakusei-no dare-ka
'some student (=one of them)'
c. jyuu-nin-to-ka-no gakusei,
'some ten students (=approx. ten)' gakusei jyuu-nin-to-ka
d. Tetsuya-ka Akira(-ka)
'Tetsuya or Akira'
e. Dare-ga odorimasu ka
'Who dances?'
f. Akira-ga odorimasu ka
'Does Akira dance?'
a. dare-mo
'everyone/anyone' (dep. on stress)
b. jyuu-nin-mo-no gakusei, gakusei jyuu-nin-mo
c. Tetsuya-mo Akira-mo
d. Tetsuya-mo
'as many as ten students'
'both Tetsuya and Akira'
'also/even Tetsuya' (dep. on stress)

In the spirit of section 2.4, we have the following main questions. Do the above data sets represent etymological freak accidents? If not, are the $k a$ and $m o$ particles multi-functional, or do they admit of unified semantic analyses? If yes, what kind of semantic analyses?

\subsection{The cross-linguistic significance of the $k a$ and the mo families}

3.2.1 Are the Japanese data in section 3.1.2 cross-linguistically significant? Haspelmath (1997) doubts the significance of what we dub "the $k a$ family".

"When we go beyond the Japanese data, the empirical evidence confirms that there is no direct formal connection between 'or' and existential indefinites... First of all, although many languages have indefiniteness markers that are formally identical to disjunctive conjunctions, the situation in Japanese is quite exceptional. ... Most of the 'or' indefinites in [Japanese, Kannada, Korean, Russian, Hungarian, Portuguese, Basque, Latvian, Romanian, Ossetic, Nanay, Hausa, and West Greenlandic] are primarily free-choice indefinites, not non-emphatic indefinites like Japanese WH-ka. The only exception[s] are Kannada and Nanay, which are specific (and partially Russian and West Greenlandic, insofar as these forms can also be used in irrealis-non-specific

\footnotetext{
${ }^{4}$ For example, Kobuchi-Philip (2010) discusses gakusei-ga nan-nin-mo hashitta 'Many students ran' and proposes that this interpretation is due to a pragmatic effect. We set this use of mo aside.
} 
functions). ... The Japanese situation does not even seem to represent a tendency....

[W] hy is 'or' used in indefinite pronouns at all? ... It could be that both 'or' and the indefiniteness marker arise from the same source independently...

(368) 'want'/'it may be'

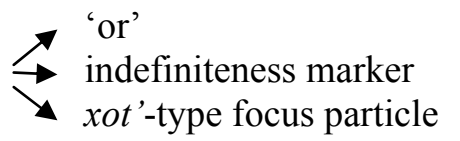

$\rightarrow$ indefinite-

ness marker"

(Haspelmath 1997: 165-9)

Since Hungarian is one of the languages on which Haspelmath bases his conclusions, it is of some interest to take a closer look at Hungarian. Haspelmath's main source is Hunyadi (1987), an article that specifically aimed at explaining the behavior of the particles mind 'every' and akár 'any.' Hunyadi's claims are in line with Haspelmath's positive conclusion above. But there are other particles in Hungarian, highly relevant to Haspelmath's negative conclusion, that neither Hunyadi, nor Haspelmath's other sources happened to address. The data below, i.e. the identification of the morphemes and their interpretations, come from the Historical-Etymological Dictionary of Hungarian (1967-1984).

The etymological dictionary supports Hunyadi's and Haspelmath's idea that free-choice akár (quantificational and connective) is related to akar 'want'. However, the dictionary also presents a range of elements that are related to vala'some', the component of non-emphatic, specific indefinites. Vagy serves as the run-of-the-mill cross-categorial disjunction in Hungarian. In addition, vagy means 'approximately, at least' when attached to a numeral. The dictionary relates vala- 'some' and vagy 'or; approximately, at least' to the participial stem val- of the existential verb and to its affricative finite allomorph vagy- (vagyok, vagy, vagyon $>$ van, etc.), respectively.

In other words, the functions of Japanese $k a$ are mirrored by Hungarian vala/vagy, except for its question-marker (interrogative clause-type indicator) function, which Haspelmath did not even consider. ${ }^{5,6}$

${ }^{5}$ Regarding (a)-(b), notice that English some leads a double life as a bound morpheme (as in someone) and as a determiner (as in some doctor 'a doctor whose identity is unknown or irrelevant'). In the latter role it is probably accompanied by a silent element that surfaces in Hungarian and German. Compare:

(i) vala-ki SOME-PERSON 'someone' irgend-wer SOME-PERSON 'someone'

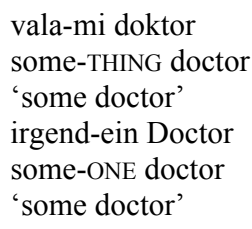

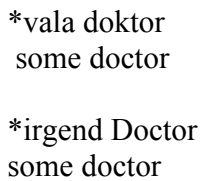

Hungarian

German 

a. valaki
'someone'
b. vala-mi diák
'some student (=whose identity is
unknown or irrelevant)'
c. vala-mi tíz diák
'some ten students (=approx. ten)'
d. Kati vagy Mari
'Kate or Mary'
e. vagy Kati vagy Mari
f. vagy tíz diák
'either Kate or Mary, not both'
g. vagy-, val-
'some ten students (=approx. ten)'
allomorphs of 'be' (existential, locative, predicative copula)
h. vajon
'puzzlement' (optional modifier)

Moreover, the disjunctions $A$ vagy $B$ and $A-k a B$ are both positive polarity items of the same type as something (Szabolcsi 2002, Goro \& Akiba 2004, Crain \& Thornton 2006), which further supports their semantic relationship to indefinite pronouns. Contrary to Haspelmath's impression, Hungarian has a robust set of elements that exemplify those properties of Japanese $k a$ that he deems crosslinguistically exceptional.

To clarify the issue of question markers, Hungarian has no overt interrogative clause-type indicator in constituent questions. It has a clause-type indicator that is obligatory in embedded yes/no questions and is in complementary distribution with yes/no question intonation in main-clause questions: the morpheme $-e$, suffixed to the finite verb. This suffix is clearly not related to vala/vagy. To save space, only embedded examples are given below.

a. Kíváncsi vagyok / Mondd meg hogy félnek-*(e). curious be.1sg tell.imp.2sg perf SUBORD afraid.3pl-Y/N 'I am curious / Tell me whether they are afraid'

b. Kíváncsi vagyok / Mondd meg hogy ki fél-(*e). curious be.1sg tell.imp.2sg part SUBORD who afraid.3sg-Y/N 'I am curious / Tell me who is afraid'

Valami doktor corresponds to Japanese (to)aru isha 'some doctor,' not to isha-no dare-ka. The latter is specific in Enç's (1991) sense: it refers to an unspecified member of a previously mentioned group.

${ }^{6}$ Doubled vagy in (21e), much like Russian doubled ili and French doubled ou, has, roughly, an exclusive disjunction interpretation. The literature on Japanese and Sinhala does not mention an exclusive interpretation, although Japansese $k a$ may, and Sinhala do must, appear on both disjuncts. Note also that English either...or ... can, but need not, be exclusive. The effect of doubling in Hungarian, Russian, and French thus seems like a separate matter. 
Gärtner \& Gyuris (2007) discuss the particle vajon. Vajon is not a clause-type indicator, it is an optional question modifier that expresses puzzlement in both yes/no and constituent questions. It is only acceptable when the answer is neither known, nor is directly requested. Vajon occurs equally in main and embedded questions; only embedded examples are given below. The use of 'might' in the idiomatic translations merely approximates the meaning. Vajon is etymologically related to vala/vagy; understandably, G\&G's formal pragmatic paper does not mention this fact.

a. Kíváncsi vagyok / *Mondd meg hogy vajon félnek-e. curious be.1sg tell.imp.2sg perf SUBORD VAJON afraid.3pl-Y/N 'I am curious whether they might be afraid' unacceptable in 'Tell me (I know, etc.) whether they might be afraid'

b. Kíváncsi vagyok / *Mondd meg hogy vajon ki fél. curious be.1sg tell.imp.2sg perf SUBORD VAJON who afraid.3sg 'I am curious who might be afraid' unacceptable in 'Tell me (I know, etc.) who might be afraid'

3.2.2 Let us turn to the mo-family. The cross-linguistically prevalent fact that the particles expressing 'every', 'any', 'also', and 'even' are related has been studied from both a semantic and a typological perspective, most prominently by Gil $(1995,2008)$; see Gil's comments in section 4.3.

Many of the roles played by members of the mo-family are replicated in Hungarian but, remarkably, by distinct elements, mind vs. is. Interestingly, mind and is overlap in their distributive conjunction interpretation ('both'). $E s$ 'and' is etymologically related to $i s$, but it is not an inherently distributive conjunction. ${ }^{7}$

$\begin{array}{ll}\text { a. } & \text { mindenki } \\ \text { b. } & \text { minden diák } \\ \text { c. } & \text { A diákok mind VP. } \\ \text { d. } & \text { mind Kati mind Mari } \\ \text { e. } & \text { Kati is (és) Mari is } \\ \text { f. } & \text { Kati is } \\ \text { g. } & \text { (még) Kati is } \\ \text { h. } & \text { tíz diák is }\end{array}$

'everyone'
'every student'
'The students all VP'
'both Kate and Mary'
'both Kate and Mary'
'Kate too
'even Kate'
'as many as ten students'

${ }^{7}$ See Koopman \& Szabolcsi (2000: 201) for discussion of so-called emphatic is, exemplified in (24i). Emphatic is attaches to the main polarity projection of the clause (here, to the focus Kati), and expresses that the situation described by the clause is as was expected. 
i. [... és] Kati is lett az első. ' ' [... and] indeed Kate came in first

j. Kati és Mari 'Kate and Mary'

3.2.3 The following tables summarize the main roles of $\mathrm{ka}$, mo, and their Hungarian counterparts.

\begin{tabular}{|l|l|l|}
\hline$(25)$ & \multicolumn{1}{|c|}{ Japanese } & \multicolumn{1}{c|}{ Hungarian } \\
\hline indefinite pronoun & dare-ka & vala-ki \\
\hline number is approximate & $10-C L-T O P-k a$ & vagy 10, vala-mi 10 \\
\hline disjunction & X-ka Y(-ka) & X vagy Y \\
\hline constituent-question marker & {$[$ CP dare ...] ka } & -- \\
\hline yes/no question marker & {$[$ CP ... $] \mathrm{ka}$} & -- \\
\hline question modifier & -- & vaj-on $[\mathrm{CP} \ldots]$. \\
\hline existential verb stem & -- & vagy-, val- \\
\hline
\end{tabular}

\begin{tabular}{|l|l|l|l|}
\hline$(26)$ & \multicolumn{1}{|c|}{ Japanese } & \multicolumn{2}{c|}{ Hungarian } \\
\hline universal/negative pronoun & dare-mo & mind-en-ki & \\
\hline floating universal quantifier & -- & mind [vP ...] & \\
\hline distributive conjunction & $\mathrm{X}-\mathrm{mo} \mathrm{Y}$-mo & mind X mind Y & $\mathrm{X}$ is Y is \\
\hline additive/scalar particle & $\mathrm{X}-\mathrm{mo}$ & & $\mathrm{X}$ is \\
\hline number is large & $10-\mathrm{CL}-\mathrm{mo}$ & & $10 \mathrm{~N}$ is \\
\hline
\end{tabular}

3.2.4 The broader cross-linguistic picture. Going beyond these languages, Slade (2011) demonstrates that Old Malayalam -oo occurs in all the roles of Japanese $k a$, and Modern Sinhala do in almost all its roles; declarative, as opposed to interrogative, disjunction is the exception. Similar data are discussed by Ramchand (1997) for Bengali; Jayaseelan (2001, 2011) for Malayalam; Amritavalli (2003) for Kannada; Borzdyko (2004) for Belorussian; Paul (2005) for Malagasy; Zimmermann (2009) for Korean and Hausa; Cable (2010) for Tlingit.

Xiang (2008) discusses multiple roles of dou in Mandarin, and Bumford, Whang, \& $\mathrm{Zu}$ (2011) observe systematic similarities between Japanese $m o$ and Mandarin/Cantonese dou. We turn to these in section 6.

The moral, we believe, is that it is legitimate and potentially rewarding to investigate these data sets from the perspective of compositional semantics. But indeed, languages are not all alike. The task is to make sense of the shared patterns as well as the cross-linguistic differences, as one would do in syntax or phonology. 


\section{One unifying perspective: Boolean semantics}

Section 4 discusses a unifying perspective for all the above-discussed particles in terms of Boolean operations, and mentions some problematic points.

\section{$4.1 \exists$ and $\vee, \forall$ and $\wedge$}

We have seen that Hungarian vala/vagy and Japanese $k a$ both function as disjunctions and participate in the formation of existential/indefinite pronouns. In addition, vala/vagy is also the stem of the existential verb, and $k a$ is a questionmarker (clause-type indicator, Force head). We have also seen that Hungarian mind(en) and is jointly express distributive conjunction, 'also,' and 'even,' and form universal pronouns; Japanese mo does all these single-handedly.

Can these interpretations be unified? As is observed by Haspelmath (1997: $165)$ with reference to Reichenbach (1947: 92) and others, a natural starting point for unification is the fact that existential quantification is reducible to disjunction, and universal quantification to conjunction. Assume that we have a finite universe where all individuals have names, for example, $U=$ KKate, Mary, Joe $\}$. Then, the expressions on the left-hand side are equivalent to those on the righthand side:

(27) Someone dances iff $\exists x[\operatorname{dance}(\mathrm{x})]$

Kate dances or Mary dances or Joe dances dance $($ kate $) \vee$ dance(mary) $\vee$ dance $($ joe $)$

Everyone dances iff Kate dances and Mary dances and Joe dances $\forall \mathrm{x}[$ dance $(\mathrm{x})] \quad$ dance $($ kate $) \wedge$ dance $($ mary $) \wedge$ dance $($ joe $)$

The simple facts above may provide a unified semantics for our particles, because $\exists / \vee$ can be seen as being at work in all uses of $k a$ and vala/vagy, and $\forall / \wedge$ can be seen as being at work in all uses of mo, mind, and is.

Being "at work" means that the operator plays a major role in explicating the semantics of the given expression, although it may or may not exhaust its semantics. To demonstrate this, we have to go a little beyond the classical observations.

\subsection{Question-markers in the $\exists / \vee$ family}

In the $\exists / \vee$ family, especially the question-marker role of $k a$ deserves some comment. Both Hamblin $(1958,1973)$ and Karttunen (1977) interpret a question as the set of propositions that serve as its possible answers. Unlike Hamblin, 
Karttunen also requires answers to be true; we set this aside for the moment. Neither theory requires answers to be exhaustive. Kate dances as well as Mary dances count as separate and true answers if both individuals dance.

In the case of yes/no questions, there are just two possible answers, the positive and the negative ones. In the case of individual wh-questions there are as many possible answers as there are individuals in the universe.

$$
\begin{aligned}
& \text { Does Kate dance? à la Karttunen } \\
& \text { (p: } \mathrm{p}=\{\mathrm{w}: \text { dance }(\mathrm{kate})(\mathrm{w})\} \vee \mathrm{p}=\{\mathrm{w}: \neg \text { dance }(\text { kate })(\mathrm{w})\} \\
& \text { 'the set of propositions that are identical to "Kate dances" or to } \\
& \text { "Kate doesn't dance", }
\end{aligned}
$$

$$
\begin{aligned}
& \text { Who dances? à la Karttunen } \\
& \begin{aligned}
\{\mathrm{p}: \mathrm{p}=\{\mathrm{w}: \text { dance }(\text { kate })(\mathrm{w})\} \vee \mathrm{p}=\{\mathrm{w}: \operatorname{dance}(\operatorname{mary})(\mathrm{w})\} \\
\mathrm{p}=\{\mathrm{w}: \operatorname{dance}(\mathrm{joe})(\mathrm{w})\}
\end{aligned}
\end{aligned}
$$

"the set of propositions that are identical to "Kate dances," or to "Mary dances," or to "Joe dances",

Above, the sets of possible answers are defined as $\{\mathrm{p}:(\mathrm{p}=\ldots) \vee(\mathrm{p}=\ldots) \vee \ldots\}$, a propositional disjunction schema. The same definitions can be equivalently expressed in the following ways. (30a) defines the same set as (29), because (30a) enumerates exactly those three atomic propositions that make the disjunction in (29) true in our toy universe. (30b) defines the same set as (29) and (30a): it picks out all propositions of the form " $\alpha$ dances" where $\alpha$ is one of the persons in the universe.

Who dances?

a. $\{\{\mathrm{w}:$ dance $($ kate $)(\mathrm{w})\},\{\mathrm{w}:$ dance $(\operatorname{mary})(\mathrm{w})\},\{\mathrm{w}:$ dance $(\mathrm{joe})(\mathrm{w})\}\}$

b. $\{\mathrm{p}: \exists \mathrm{x}[\mathrm{person}(\mathrm{x}) \wedge \mathrm{p}=\{\mathrm{w}: \operatorname{dance}(\mathrm{x})(\mathrm{w})\}]\}$

In other words, classical logical $\exists / \vee$ is critically used in the definition of the set of propositions that questions denote. In that sense the question-marker role of $k a$ is consistent with treating it as a member of the $\exists / \vee$ family, even though questions do not make existential assertions or disjoin propositions, i.e. $\exists / \vee$ is not the main operation in their semantics.

Recall, however, that Hungarian, for example, does not use vala/vagy as a question-marker. Is this an accidental gap? Or, does it raise a red flag and indi-

\footnotetext{
${ }^{8}$ Each proposition is identified with that set of possible worlds $\{\mathrm{w}: \ldots \mathrm{w} . .$.$\} in which the sentence is$ true. Following Montague's notation, Karttunen wrote ${ }^{\wedge}$ dance(kate) for what is written today as $\{\mathrm{w}$ : dance $(\mathrm{kate})(\mathrm{w})\}$ or, using the $\lambda$-operator, as $\lambda$ w.dance $($ kate $)(w)$.
} 
cate that unifying all uses of $k a$ in the particular way suggested above is wrong? Kobuchi-Philip (2010) proposes that $k a$ forms questions together with a silent CHOOSE function, viz. 'choose the true answer'. Something along these lines could be a natural refinement of the unification proposal because, as was pointed out right above, $\exists / \vee$ is "at work," but not the sole or main operation, in questions. One could say that Hungarian differs from Japanese in that vala/vagy fails to team up with silent CHOOSE and so it does not participate in question formation; some other operator, or combination of operators, performs that complex job. Such a solution would rest on the following assumption:

Not a bi-unique relation

It is possible for all occurrences of particle $\mathrm{P}$ to share the same semantic value $S$ without $P$ being the only particle that has that semantic value $S$.

We come back to the ka vs. vala/vagy contrast in section 5 . Whatever the ultimate conclusions may be, it is an advantage of the present approach that it brings the puzzles about the various guises of $k a$ and other operators out in the open.

\subsection{Presuppositions in the $\forall / \wedge$ family}

In the article on "Conjunctions and universal quantifiers" in the World Atlas of Language Structures (WALS), Gil (2008) comments,

"[S]ome semanticists have proposed deriving the interpretations of universal quantifiers from those of conjunctions. For example, in the Boolean Semantics of Keenan and Faltz (1986), conjunctions and universal quantifiers are both represented in terms of set-theoretic intersections.

How well do such semantic representations correspond to the observable lexical and grammatical patterns of languages? ... [O]ne might suspect that they do not correspond at all well. Thus, in English, the conjunction and and the universal quantifier every are distinct words with quite different grammatical properties.

However, a broader cross-linguistic perspective suggests that there are indeed widespread lexical and grammatical resemblances between conjunctions and universal quantifiers, thereby lending support to the logicians' analyses ...

For the purposes of the [WALS] map, conjunctions are taken to include not only forms with meanings similar to that of and, but in addition expressions that are sometimes characterized as conjunctive operators or focus particles, with meanings resembling those of also, even, another, again, and in addition the restrictive only. As for universal quantifiers, these are assumed 
to encompass not only forms with meanings such as those of every, each and all, but also expressions that are sometimes referred to as free-choice...

While the connection between conjunctions and universal quantifiers is well-motivated semantically, it is still necessary to work out the detailed mechanisms by which the relevant complex expressions derive their meanings from those of their constituent parts."

(Gil 2008; emphases in the original)

For the purposes of the WALS classification, Gil assumes that conjunctive (with another common term, additive) particles are natural members of the $\forall / \wedge$ family. This requires some comment. Minimally, one has to say that Boolean conjunction $\wedge$ is "at work" in 'too, also' and 'even' but does not exhaust their contribution. This weaker claim is intuitively correct, but its technical implementation is not easy. Both Kate, too, dances and Even Kate dances are thought to presuppose that someone other than Kate dances.

Kate, too, dances

Even Kate dances

both entail "someone other than Kate dances, and Kate dances"

Presuppositions are often treated as definedness conditions: the sentence containing too or even is neither true nor false if the presupposition is not satisfied. If the conjunctive contribution of too and even is only a definedness condition and not an assertion, then it is not justified to group them with 'every' and 'and'. In another approach, Schlenker (2008) proposes to treat presupposed propositions as conjuncts that are suppressed under appropriate pragmatic circumstances. This may be more of a justification for the assimilation of 'too, also' and 'even' to 'and'. But, this implementation would overgenerate, because it would predict that all expressions that carry a presupposition of any kind are candidates for having a $\forall / \wedge$ marker, including definite descriptions, factive verbs, inchoative verbs, etc. This does not seem to be the case in any language we are aware of. For example, factive verbs such as know and regret presuppose the truth of the complement clause, but neither these verbs, nor their complements are marked with mo-like elements.

In sum, while the intuition that $\wedge$ is part of the contribution of 'too' and 'even' seems correct, it is not obvious exactly how that intuition should be made precise. It is also relevant to point out that although Japanese mo and Hungarian mind(en) each play many roles, neither functions as plain 'and'. Japanese 'and' is -to, and Hungarian 'and' is és. Hungarian is and és are etymologically related, 
but they are never interchangeable. In Hungarian, only és supports collective and cumulative readings, and only és serves as a sequencing sentential connective:

(33) Kati és Mari megevett összesen tíz almát. 'Kate and Mary ate altogether ten apples (collectively or cumulatively)'

(34) Lement a nap, és lehült a levegő.

'The sun went down, and the air cooled'

Furthermore, the particle mind- that forms universals is entirely distinct from és/is, although the paired versions (mind $A$, mind $B$ and $A$ is, $B$ is) coincide in meaning 'both, as well as'; recall the table in (26).

As Gil notes, a compositional analysis that unites these elements under the $\forall / \wedge$ roof, if feasible, requires much further work. It may involve the semantic decomposition of the particles and the postulation of various silent elements, somewhat in the spirit of Kobuchi-Philip's proposal for $k a+$ CHOOSE.

\subsection{Making the logic more general}

The unresolved issues notwithstanding, it is important to point out that recognizing the $\exists / \vee$ and the $\forall / \wedge$ relationships does not really commit us to the assumption that the universe is finite and every one of its inhabitants has its own name. (The second assumption would be more devastating. Whether or not the infinity of the world is linguistically significant, the expressions every fork and some fork definitely do not require for each fork to have its own name.) These constraints stem from expressing the relationships using predicate logic and propositional logic, as we did for expository purposes. But it is easy to move to a more general domain that is not constrained that way.

Existential quantification and disjunction both fall under the rubric of taking the set-theoretic union of more abstract semantic objects that we may use to interpret linguistic expressions; similarly, universal quantification and conjunction both fall under the rubric of taking intersections; see especially Keenan \& Faltz (1986). For example, if DPs are assumed to denote generalized quantifiers, i.e. sets of properties, then dare- $k a$ 'someone' denotes the union of the sets of properties that at least one person has in the possibly infinite and nameless universe; and Akira-ga odorimasu ka 'Does Akira dance?' denotes the union of the set of propositions equivalent to "Akira dances" with the set of propositions equivalent to "Akira doesn't dance," and so on.

The preliminary unification hypothesis in section 4.1 can be stated in terms of Boolean operations as follows: 
$k a$, vala/vagy are union operators.

mo, mind(en), és, is are intersection operators.

Even more generally, disjunction and union are both special cases of the join operation of lattice theory that finds the least upper bound of two appropriate things, without restricting them to be propositions or sets. Likewise, conjunction and intersection are both special cases of the meet operation of lattice theory that finds the greatest lower bound. (See Landman 1991: Ch. 6 for a thorough introduction to lattices, and Szabolcsi $1997 \mathrm{~b}$ for a very brief one.) We may want to use these more general notions if it turns out that $k a, m o$, and their brothers also operate on objects that are not Boolean in nature. Events and collectives would be such. Furthermore, as Roelofsen (2012) points out, lattice theory provides an umbrella under which both the Boolean and the alternative-semantic views can be subsumed. Section 5 explores this latter view.

\section{Another unifying perspective: alternatives and issue-raising}

Section 5 reviews how Inquisitive Semantics has assimilated the interpretations of disjunctions and indefinites to that of questions, thus providing a more perfect match with members of the $k a$-family. (Whether this perspective will extend to the mo-family is left open.) The section goes on to look at crosslinguistic differences and raises the question whether they are syntactic or semantic in nature.

\subsection{The ka-family in Inquisitive Semantics}

Starting with Discourse Representation Theory (DRT) and Dynamic Semantics (DS) in the 1980s, semantic theories became attentive to aspects of meaning beyond plain truth-conditions. DRT and DS were specifically concerned with anaphora and presupposition projection. Roughly at the same time, Rooth (1985) proposed a two-dimensional semantics, in which the role of focus is to introduce a set of contextually relevant alternatives. Focus alternatives either remain hanging in the air, or are used by operators, such as only, that quantify over them; if that happens, they get incorporated into the ordinary meaning of the expression. Rooth's set of focus alternatives and Hamblin's set of possible answers are the exact same set and, moreover, they are built and expanded in the same way in the course of assembling the sentence from its constituent parts (see Rooth 1992: 84 for discussion of the parallelism). 
(37) Who dances? à la Hamblin:

$\{\{\mathrm{w}:$ dance $($ kate $)(w)\},\{\mathrm{w}: \operatorname{dance}(\operatorname{mary})(\mathrm{w})\},\{\mathrm{w}:$ dance $(\mathrm{joe})(\mathrm{w})\}\}$

(38) $[K A T E]_{\mathrm{F}}$ dances à la Rooth:

ordinary meaning: $\{\mathrm{w}$ : dance $($ kate $)(\mathrm{w})\}$

focus alternatives: $\{\{\mathrm{w}: \operatorname{dance}(\mathrm{kate})(\mathrm{w})\},\{\mathrm{w}:$ dance $(\operatorname{mary})(\mathrm{w})\}$, $\{\mathrm{w}:$ dance $(\mathrm{joe})(\mathrm{w})\}\}$

Formally speaking, these sets of propositions are familiar semantic objects, but now a new intuition is attached to them.

Kratzer \& Shimoyama (2002) proposed to recast semantic composition in general, and quantification in particular, in terms of Hamblin's semantics, also known as alternative semantics (i.e. semantics based on alternatives). On this approach, all expressions denote sets of alternatives. The big difference is that expressions like John and sleep denote singleton sets of alternatives, \{John\} and \{sleep\}: no real choice is offered. In contrast, question words/indeterminate pronouns (who/one) introduce genuine, i.e. non-singleton sets of alternatives. Syntactic merge corresponds to merging alternatives; if there is a genuine choice, it projects up to the larger expression. Operators like only and mo assert that just one, or that every single one, of the alternatives is true. If no operator quantifies over the alternatives, silent existential closure is invoked to assert that at least one of the alternatives is true. ${ }^{9}$

Crucially to us, Alonso-Ovalle (2006) makes the case for a new treatment of disjunction, with reference to conditionals. He argues that or forms a set of propositions, as in (39), and not a single proposition whose truth may be guaranteed in multiple ways, as in $(40 \mathrm{a}, \mathrm{b})$ :

(39) Kate dances, or Mary dances, or Joe dances à la Alonso-Ovalle: $\{\{$ w: dance $($ kate $)(w)\},\{$ w: dance $($ mary $)(w)\},\{$ w: dance $(j o e)(w)\}\}$

(40) a. Kate dances, or Mary dances, or Joe dances in classical logic: $\{\mathrm{w}: \operatorname{dance}(\mathrm{kate})(\mathrm{w})\} \cup\{\mathrm{w}: \operatorname{dance}(\operatorname{mary})(\mathrm{w})\} \cup\{\mathrm{w}:$ dance $(\mathrm{joe})(\mathrm{w})\}$

b. Kate dances, or Mary dances, or Joe dances in an alternative semantics that implements classical logic:

$\{\{\mathrm{w}:$ dance $($ kate $)(\mathrm{w})\} \cup\{\mathrm{w}:$ dance $($ mary $)(\mathrm{w})\} \cup\{\mathrm{w}:$ dance $(\mathrm{joe})(\mathrm{w})\}\}$

\footnotetext{
${ }^{9}$ See Abels \& Martí (2011) for criticism of that aspect of Kratzer \& Shimoyama's system that it quantifies over propositions, and Shan (2002) for another problem with their propositional logic.
} 
Inquisitive Semantics (Mascarenhas 2009; Groenendijk \& Roelofsen 2009; see also the Inquisitive Semantics Home Page) is a new development of this approach that focuses on the cases in which neither a quantificational operator, nor existential closure applies to the set of alternatives. In that case the sentence is dedicated to raising an issue by presenting the set of alternatives and demanding that one of them be chosen. Central to Inquisitive Semantics is the observation that questions and "main" disjunctions share this basic feature of inquisitiveness. Notice that the interpretation of Kate dances, or Mary dances, or Joe dances in (39) is identical to that of Who dances? in (37). The same holds for indefinites, see (41), as pointed out especially by AnderBois (2012):

Someone dances à la AnderBois:

$\{\{\mathrm{w}: \operatorname{dance}($ kate $)(\mathrm{w})\},\{\mathrm{w}: \operatorname{dance}(\operatorname{mary})(\mathrm{w})\},\{\mathrm{w}: \operatorname{dance}(j o e)(\mathrm{w})\}\}$

In sum, the semantics of alternatives and especially Inquisitive Semantics unites the core of the interpretations of questions, disjunctions, and indefinites under one umbrella. The claim is that they all contribute issues, viz. sets of open possibilities, to discourse.

Inquisitive Semanticists often use diagrams to depict issues. In that spirit, the diagram below depicts the issue that each of (i) Who dances?, (ii) Kate dances, or Mary dances, or Joe dances, and (iii) Someone dances raises in our universe.

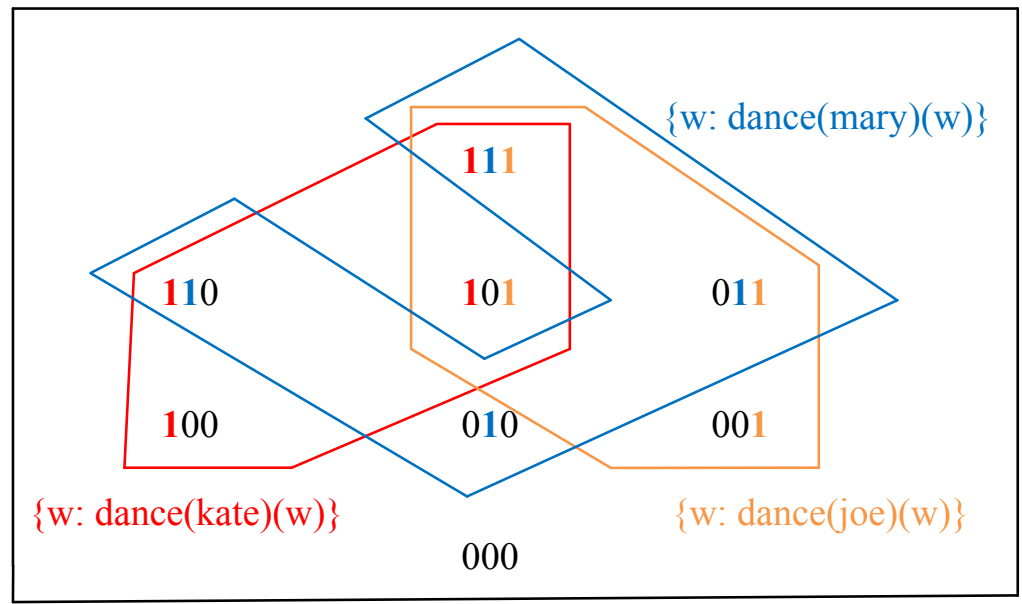

In the diagram, every world is represented with three digits that specify the truth values of three atomic sentences (the only sentences that we care about). For example, "100" stands for "Kate dances, Mary does not, Joe does not," and the red box encloses the set of all those worlds in which Kate dances is true. Each of 
the boxed areas constitutes a possibility, and the three possibilities together constitute the issue: we are uncertain as to which area the actual world lies in. The world " 000 " in which all three sentences are false is excluded, in the declarative cases by assertion, and in the question case by presupposition.

In section 4 we suggested that the uses of Japanese $k a$ form a natural class, because the Boolean union (join) operation occurs in the semantics of questions, disjunctions, and indefinites. Recall that on that approach questions were a little bit sticking out from under the umbrella. In the present section we reviewed theories that revise the traditional interpretations of disjunctions and indefinites and make them more similar to the interpretation of questions. It seems, therefore, that the Inquisitive Semantic perspective offers a more perfect unification of these three roles of $k a$.

\subsection{Cross-linguistic differences in inquisitiveness}

Slade (2011) discusses cross-linguistic differences in the distribution of Japanese $k a$ and its counterparts in Sinhala, Malayalam, and Tlingit. (For example, Tlingit sá participates in indefinites and wh-questions, but not in disjunctions or yes/no questions; see Cable (2010).) Slade proposes that all the particles share the same semantics, and the cross-linguistic differences in their distribution are morpho-syntactic: they can be characterized in terms of (un)interpretable and (un)valued features. ${ }^{10}$ Slade's analysis is elegant, but we would like to consider the possibility that at least some of the cross-linguistic differences, for example those between Japanese and Hungarian, have more to do with semantics.

Let us look back on the data regarding Hungarian vala/vagy. Although the roles of $k a$ and vala/vagy overlap, each has an important role that the other lacks.

\begin{tabular}{|l|l|l|l|l|l|}
\hline$(42)$ & $k a$ & question-marker & disjunction & indefinite & \\
\hline & vala/vagy & & disjunction & indefinite & exist. verb \\
\hline
\end{tabular}

The fact that vala/vagy does not function as a question-marker but it does as a verb that asserts existence may suggest that the common denominator of its uses is the classical $\exists / \vee$ discussed in section 4 . In contrast, the common denominator of the uses of $k a$ is readily characterized as issue-raising, which does not subsume the assertion of existence. The overlap can be accommodated in either way,

${ }^{10}$ Following Hagstrom (1998), Cable (2010) extends the choice-functional analysis of $k a$ in indefinites to $k a$ in constituent questions, and Slade (2011) further extends it to yes/no questions and disjunctions. We do not follow these authors, but arguing against the choice-functional semantics is not a goal of the present paper. 
and it should be. As far as we can see, Hungarian sentences involving 'or' and 'someone' do not differ substantially from their Japanese counterparts.

On the other hand, questions are not quite alien to vala/vagy. In section 3.2.1 we noted the existence of the optional question-modifier vajon and the fact that it is only acceptable in questions that express "puzzlement" without an ability, or attempt, to resolve the issue. A vajon-modified interrogative may be the complement of 'wonder' or 'be curious,' but not of 'know,' 'tell,' or even 'ask', and as a main clause it likewise cannot be used to seek a straight answer. Going beyond Gärtner \& Gyuris (2007), we suggest that vajon indicates issue-raising in a pure form. Its distribution makes it plain that issue-raising and answer-seeking are different things. Inquisitive Semantics is not yet equipped to make this distinction, but analysis of the data at hand is expected to help further work.

We see, then, that the Hungarian relatives of $k a$ are sometimes less inquisitive and sometimes more inquisitive than $k a$. We hypothesize that vala/vagy and $k a$ share a core and diverge in their surface distribution, because they are aided by, or are conflated with, different silent operators. The propositional logic version of Inquisitive Semantics already has a declarative operator ! ("double negation") and an interrogative operator? ("or not"); see Ciardelli et al. (2012: Ch 4). The former, ! eliminates the issue-raising potential of a sentence and thus could be used to turn an inquisitive operator into a Boolean one. The latter, ? creates a yes/no question, and thus could be used to turn a Boolean operator into an inquisitive one. Kobuchi-Philip's CHOOSE might make yet another pertinent silent actor.

Even though we are already breaking words down into morphemes, the analysis needs to be finer-grained. The cross-linguistic investigations can be expected to put flesh on the bones and help address the theoretical questions in empirically motivated ways.

\subsection{Updating the logic}

How different is the Inquisitive perspective from the Boolean perspective? Roelofsen (2012) points out that, abstractly, the two are very similar. For example, on both perspectives or is interpreted as the join operation in a Heyting algebra. ${ }^{11}$ But in the case of classical logic, that Heyting algebra is also a Boolean algebra, whereas in the semantics of alternatives, it is not. Therefore, from a logical point of view, it would make sense if we found that operators like $k a$ basically embody the more general notion, with special cases surfacing in different constructions; and it would also make sense if we found that the Boolean and

\footnotetext{
${ }^{11}$ See http://en.wikipedia.org/wiki/Heyting_algebra.
} 
the non-Boolean versions are separate items, and languages differ as to which of them they have. In the latter case the grand generalization would only obtain at some meta-level.

\subsection{Issues in the mo-family?}

Although Heyting-algebras happily accommodate the meet operation, the issue-raising perspective outlined in section 5 does not immediately suggest a comparable unifying principle for $m o$ and its cross-linguistic relatives, beyond the general suggestion in Kratzer \& Shimoyama that $m o$ is a quantifier over alternatives. We leave the exploration of extending this approach to the mofamily to further research, and consider existing non-Inquisitive approaches in section 6.

\section{Competing insights for mo and dou}

Section 6 observes that the Japanese mo and Chinese dou have a highly similar distribution, and lays out the functional similarities, as well as important differences. There is extensive literature pertaining to mo and dou, but comparative studies are rare or non-existent. Moreover, typical approaches only concern themselves with one facet of each particle. This section considers two of the rare accounts that strive to be relatively comprehensive - Kobuchi-Philip (2008, 2009, 2010) for mo and Xiang (2008) for dou.

\subsection{Mo and dou, similarities and differences}

To lay some groundwork for further research, the present section sets out to compare Japanese mo and Chinese (primarily Mandarin) dou. Bumford, Whang, $\& \mathrm{Zu}$ (2011) find that the two particles have a highly similar distribution and support highly similar interpretations; but minor distributional and interpretive differences remain. Drawing on this work, section 6.1 surveys the data, and 6.2 considers an account for each of mo and dou from the literature. The two accounts are based on quite different intuitions that correlate with certain descriptive differences between the two particles. 


\subsubsection{Similarities}

[A] Both mo and (Cantonese, though not Mandarin) dou function as focussensitive additive particles (cf. too, also).

Like English 'also', mo is focus sensitive, and presupposes that at least one alternative in the sentence's focus set has been established in the common ground. Examples (43) and (44) show that mo can be attached to both the subject and object of a sentence, superseding the default nominative or accusative case marker. The noun phrase that $m o$ attaches to is interpreted as focus, with no special prosody required for the reading.

$\begin{array}{llll}\begin{array}{l}\text { kare-mo } \\ \text { he-MO sono-gakusei-wo }\end{array} & \begin{array}{l}\text { tetsudatteage-ta } \\ \text { that-student-ACC }\end{array} & \text { (Japanese) } \\ \text { ' }[\mathrm{He}]_{\mathrm{F}} \text { also helped that student' } & & \\ & & \\ \text { kare-ga } \quad \text { sono-gakusei-mo } & \text { tetsudatteage-ta } & \text { (Japanese) } \\ \text { he-NOM that-student-MO } & \text { help-PAST } & \\ \text { 'He helped [that student }]_{\mathrm{F}} \text { also' } & & \end{array}$

While Mandarin does not have a corresponding usage of dou as an additive particle, Cantonese does. In this dialect, dou functions just as mo in the examples above, although unlike Japanese, the particle has to immediately precede the main verb. Example (45) may have different presuppositions depending on the placement of the stress. When the subject receives a focus accent as in (45a), the sentence presupposes that someone else wants to eat ice-cream. When the verb sik 'eat' is stressed as in (45b), on the other hand, it presupposes that the subject wants to do something else. Note that the F-marked phrases (i.e., constituents that contain bearers of pitch accents) have to be adjacent to dou. Thus the object moves to the preverbal position in (46) when it is focused.
a. $\left[\text { ngo }^{5}\right]_{\mathrm{F}} \quad$ dou $^{1} \quad$ soeng $^{2} \quad$ sik $^{6} \quad$ syut $^{3}$ gou $^{1}$ I DOU want eat ice-cream
(Cantonese)
Assertion: I want to eat ice-cream
Presupposition: someone else [also] wants to eat ice-cream

b. ngo $^{5}$ dou $^{1} \quad\left[\begin{array}{lll}\text { soeng }^{2} & \text { sik }^{6} & \left.\text { syut }^{3} \text { gou }^{1}\right]_{\mathrm{F}}\end{array}\right.$

(Cantonese)

I DOU want eat ice-cream

Assertion: I want to eat ice-cream

Presupposition: I want to do something else [also] 


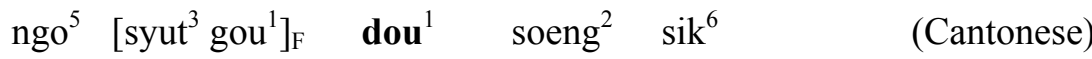

$$
\begin{aligned}
& \text { I ice-cream DOU want eat } \\
& \text { 'I want to eat [ice-cream }]_{\mathrm{F}} \text { also' }
\end{aligned}
$$

[B] Both mo and dou function as focus-sensitive scalar particles (cf. even).

While it is not the only method, both mo and dou in their respective languages can be used to induce focus-sensitive scalar presuppositions in the appropriate contexts with appropriate intonations. Very much like English 'even', sentences with $m o$ and dou presuppose that their ordinary denotations are unlikely propositions in their focus sets to obtain. For example in Japanese, when stress is placed on kare 'he' as in (47), the speaker presupposes that of all the people in the relevant context, 'he' was an unlikely person to help the student in question. Likewise in (48), the presupposition is that of all the people in the relevant context, sono gakusei 'that student' was an unlikely person for 'he' to help.

$$
\begin{array}{lll}
{[\text { kare }]_{\mathrm{F}}-\mathrm{mo}} & \text { sono-gakusei-wo tetsudatteage-ta } & \text { (Japanese) } \\
\text { he-MO } & \text { that-student-ACC help-PAST } \\
\text { 'Even }[\text { he }]_{\mathrm{F}} \text { helped that student' } &
\end{array}
$$

$$
\begin{array}{llll}
\text { kare-ga } \quad[\text { sono-gakusei }]_{\mathrm{F}}-\mathbf{m o} & \begin{array}{l}
\text { tetsudatteage-ta } \\
\text { help-PAST }
\end{array} & \text { (Japanese) } \\
\text { he-NOM that-student-MO } & \text { helped even [that student }]_{\mathrm{F}} &
\end{array}
$$

The examples below show that the same is true for dou in Mandarin. Still, dou has to immediately precede the verb and the F-marked phrase has to be adjacent to $\mathrm{dou}$.
a. $[\text { wŏ }]_{\mathrm{F}}$ dōu xiăng chī xuĕgāo I DOU want eat ice-cream
(Mandarin)
Assertion: I want to eat ice-cream
Presupposition: I am the least likely person to crave for ice-cream

b. wŏ dōu xiăng chī $[\text { xuĕgāo }]_{F}$ (Mandarin) I DOU want eat ice-cream

Assertion: I want to eat ice-cream

Presupposition: Eating ice-cream is the least likely thing I would want to do 


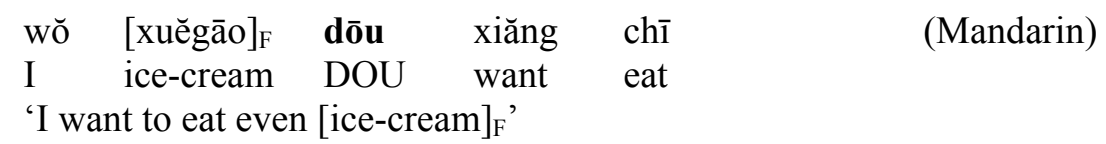

In the environment of a numeral, 'even' amounts to 'as many as'. For instance, in the examples (51) and (52) below, the presupposition is that of the number of apples 'he' could have eaten, fifteen was unexpectedly high.

$$
\begin{aligned}
& \text { kare-ga ringo-jyuugo-ko-mo tabeta (Japanese) } \\
& \text { he-NOM apple-fifteen-CL-MO eat-PAST } \\
& \text { 'He ate as many as fifteen apples' (Kobuchi-Philip 2008: 497) } \\
& \begin{array}{lllll}
\text { tā shíwŭ-gè } & \text { píngguŏ } & \text { dōu } & \text { chī-le } & \text { (Mandarin) } \\
\text { he fifteen-CL } & \text { apple } & \text { DOU } & \text { eat-ASP } &
\end{array} \\
& \text { 'He ate as many as fifteen apples' }
\end{aligned}
$$

Similarly, in a negative environment, both mo and dou, when attached to a minimal amount expression, can serve to emphasize the utter failure of a predicate to be satisfied. This effect is similar to that of not even in English.

$$
\begin{aligned}
& \text { hito-ri-mo hohoem-ana-katta } \\
& \text { one-CL-MO } \\
& \text { 'Not even a single person smiled' }
\end{aligned}
$$

(Japanese)

$$
\begin{array}{llll}
\text { yí-gè-rén dōu méi } & \text { xiào } \\
\text { one-CL-person DOU not } & \text { smile } \\
\text { 'Not a single person smiled' }
\end{array}
$$

(Kobuchi-Philip 2009: 172)

(Mandarin)

[C] Both mo and dou form universal quantifiers with indeterminate pronoun bases (cf. everyone) and with which-phrases (cf. every professor), although dou is not morphologically attached to the noun phrase and, when in subject position, it may require a generic context (Henry Chang, p.c.).

When $m o$ is attached to an indeterminate noun phrase, it results in a universal generalized quantifier. In examples (55) and (56) below, the wh-word is immediately followed by mo. ${ }^{12}$

\footnotetext{
${ }^{12}$ While beyond the focus of this paper, we should note that the dare-mo 'who-MO' construction in Japanese as in (55) is special, in that mo does not supersede the case marker in positive contexts but it does in negative contexts.
} 


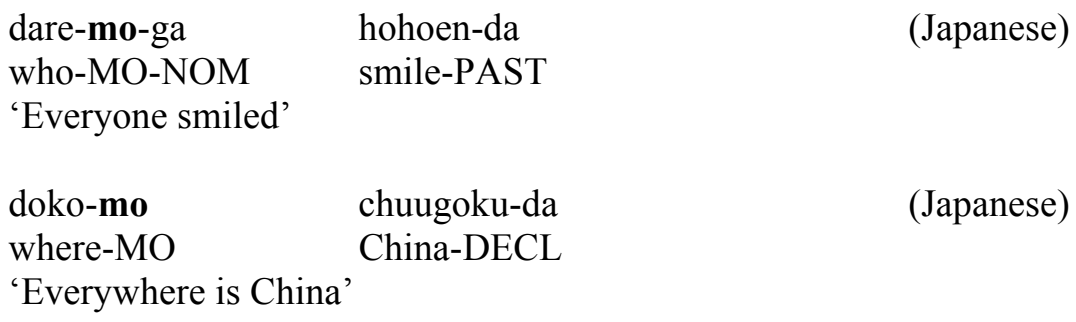

The Mandarin counterpart dou functions analogously, although unlike mo, it is not suffixed to the $w h$-words. Rather, it sticks to its preverbal position. It is the wh-word that moves to get close to dou, as shown in (58).

$$
\begin{aligned}
& \text { zhè gè wèntí, shéi dōu huì huídá } \\
& \text { this CL question who DOU be.able answer } \\
& \text { 'Everyone can answer this question' }
\end{aligned}
$$
tā năr dōu qù-guo
he where DOU go-EXP
(Mandarin)
'He's been everywhere'

When the indeterminate pronoun is 'which', both languages allow the discontinuous which ... mo/dou to flank the nominals they modify. The result in both cases is that the nominal is interpreted as a sorting key over which a subsequent predicate universally quantifies. Examples are given below.

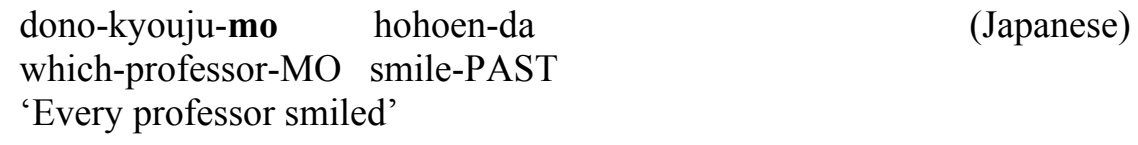

(Japanese)

'Every professor smiled'
tā nă-gè
xuéshēng
dōu Xĭhuān
(Mandarin)
he which-CL student DOU like
'He likes every student'

[D] Both mo and dou produce strictly distributive readings, but do not necessarily distribute to atomic individuals.

For instance, in the examples below, the collective reading (i.e., everybody chipped in and bought one car altogether) is unavailable. Both mo in (61) and dou in (62) give rise to distributive readings. 
(61)

$\begin{array}{lllll}\text { dare-mo-ga } & \text { ichi-dai-no } & \text { kuruma-wo } & \text { kata } & \text { (Japanese) } \\ \text { who-MO-NOM } & \text { one-CL-GEN } & \text { car-ACC } & \text { bought } & \end{array}$

'Everyone bought a car (*together)'

(62)

$\begin{array}{llllll}\text { tāmen } & \text { dōu } & \text { măi-le } & \text { yì-bù } & \text { chēzi } & \text { (Mandarin) } \\ \text { they } & \text { DOU } & \text { buy-ASP } & \text { one-CL } & \text { car } & \\ \text { 'They all (each) bought a car }(* \text { together)' } & & \text { (Lin 1998: 201) }\end{array}$

'They all (each) bought a car (*together)'

(Lin 1998: 201)

However, mo and dou do not need to distribute down to atomic individuals. Examples (63) and (64) show that they can pick out pairs and distribute over those pairs of individuals. This analysis of Mandarin is due to Lin (1998).

$$
\begin{array}{lll}
\text { dono akachan-mo } & \text { niteiru } \\
\text { which baby-MO } & \text { look alike } \\
\text { 'All babies look alike' } &
\end{array}
$$

(Japanese)

$$
\begin{array}{llll}
\text { nàxiē rén } & \text { dōu } & \text { shì fūq̄i } \\
\text { those person } & \text { DOU } & \text { be } & \text { husband-and-wife }
\end{array}
$$

'Those people are all couples'

(Mandarin)

(Lin 1998: 227)

[E] Both $m o$ and dou help form free relatives that carry a positive expectation.

Compare examples (65) and (66) for instance. In (65), with the use of mo in the first clause, the speaker is expecting to receive calls. By contrast with the ifclause as in (66), there is no such implied expectation.

$$
\begin{aligned}
& \text { (65) dare-ga denwa-shite-mo ore i-nai-tte it-te (Japanese) } \\
& \text { who-NOM phone-do-MO I be-NEG-that say-REQ } \\
& \text { 'Whoever calls, (I request that you) say that I'm not here' } \\
& \text { (66) moshi dare-ka denwa-shi-tara ore i-nai-tte it-te (Japanese) } \\
& \text { if who-KA phone-do-COND I be-NEG-that say-REQ } \\
& \text { 'If anyone calls, (I request that you) say that I'm not here' }
\end{aligned}
$$

Examples (67) and (68) are direct Mandarin translations of (65) and (66) above, and illustrate the same point. Note that unlike mo, dou occurs in the main clause, rather than the free relative clause. Sentence (67) implies that there will be people calling. This expectation disappears in (68) with the absence of $d o u$. 
(67) (wúlùn) nă-gè rén dă-diànhuà, wŏ dōu bú zài (no matter) which-CL person call I DOU not be 'Whoever calls, I'm not here' (Giannakidou \& Cheng 2006: 174)

(68) (rúguŏ) nă-gè rén dă-diànhuà, jiù shuō wŏ bú zài (if) which-CL person call then say I not be 'If anyone calls, say I'm not here' (Giannakidou \& Cheng 2006: 173-4)

\subsubsection{Differences}

[F] Only dou functions as a floating quantifier associated with a plural (cf. floated each, all).

As mentioned several times in the previous section, dou consistently occurs in the preverbal position. It can distribute over a plural that precedes it, as in (69), but the plural in question does not need to be adjacent to dou, as in (70). This is different from the focus-sensitive uses of dou (cf. (46) and (50)), which must be adjacent to the phrase that receives the focus accent.

(69) zhè-gè háizi wŏmen dōu xìhuān

(Mandarin)

this-CL child we DOU like

'We all like this child'

(70) zhè-xiē háizi wŏ dōu xìhuān

(Mandarin)

this-PL child I DOU like

'I like all these children'

The particle mo on the other hand, is suffixed to the plural nominals, although together with a $w h$-base, it also functions as an adjunct.

$\begin{array}{llll}\text { gakusei-ga dono-hito-mo } & \text { hashitta } & \text { (Japanese) } \\ \text { student-NOM } & \text { which-person-MO } & \text { ran } & \\ \text { 'Every student ran' } & & \text { (Kobuchi-Philip 2009: 179) }\end{array}$

[G] Only in Mandarin do various quantifier phrases require the support of dou.

Lin (1998) notices that certain strong quantifiers, such as meige 'every', demand the presence of dou, as in (72). 
(72)
mĕi-(yí)-gè rén
$*(\mathbf{d} \overline{\mathbf{o}} \mathbf{u})$
măi-le
shū
every-one-CL person DOU buy-ASP book
'Every person bought a book'
(Mandarin)
(Lin 1998: 219)

It is worth noting that, mei-phrases do not need dou when there is a numeral expression in the object, as shown below.

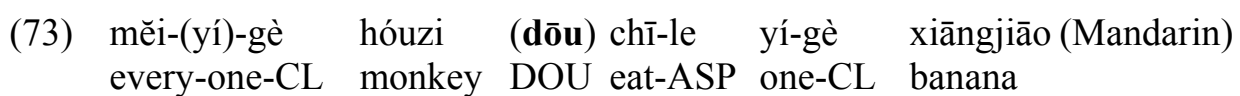
'Every monkey eats a banana'

(Huang 1996:36)

In Japanese, however, the universal quantifiers subete (distributive) and minna (collective) appear prenominally without mo.
subete-no-kyouju-ga
subete-no-gakusei-wo
tetsudatteage-ta
every-LK-professor-NOM
every-LK-student-ACC help-PAST
'Every professor helped every student'

$[\mathrm{H}]$ Adverbs of quantification are compatible with $m o$, but not with universals formed with the aid of $d o u .^{13}$

In (75), the adverb taitei 'usually' and the wh-mo phrase can co-occur.

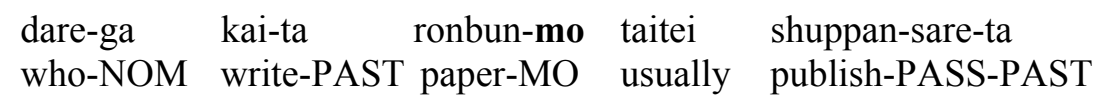
'People's papers were usually published'

(Tancredi 2004: 4)

Unlike Japanese, the universals formed with dou in Mandarin do not allow quantificational adverbs such as jingcháng 'usually', as opposed to nonquantificational adverbs such as hĕnkuài 'quickly'.

(76) shéi xiě de lùnwén hĕnkuài/*jīngcháng dōu fābiăo-le who write REL paper quickly/*usually DOU publish-ASP

'The papers that anyone wrote were quickly/usually published'

\footnotetext{
${ }^{13}$ Pair-list questions formed with every in English exhibit quantificational variability effects:

(i) Mary knows, for the most part, who everyone loves.

'For most persons, Mary knows (completely) who that person loves.'

For a discussion of the data and some of the literature, see section 4.2 of Szabolcsi (1997c). It would be interesting to see if those analyses extend to Japanese.
} 
[I] Only mo, but not dou, functions as a conjunction. Then, unlike English and, it is strictly distributive.

The sentence in (77) below does not describe a single event. Rather, there are two separate smiling events. See examples $(79)-(82)$ for further comments.
John-mo Peter-mo hohoen-da John-MO Peter-MO smile-PAST
(Japanese)
'John as well as Peter smiled; John smiled and Peter did too'

\subsubsection{Summary}

The above survey indicates that the overall distribution and interpretation of $m o$ and dou are extremely similar. In Section 3.2.2, we have also shown the parallelism between Japanese mo and Hungarian mind/is. To put all these pieces together, we extend table (26) by including Chinese in the picture.

\begin{tabular}{|l|l|l|l|l|}
\hline (78) & Japanese & \multicolumn{2}{|c|}{ Hungarian } & Chinese \\
\hline $\begin{array}{l}\text { universal/negative } \\
\text { pronoun }\end{array}$ & dare-mo & mindenki & --- & shéi dōu \\
\hline $\begin{array}{l}\text { floating universal } \\
\text { quantifier }\end{array}$ & --- & mind [vP ...] & --- & dōu [vP ...] \\
\hline $\begin{array}{l}\text { distributive con- } \\
\text { junction }\end{array}$ & X-mo Y-mo & mind X mind Y & X is Y is & --- \\
\hline $\begin{array}{l}\text { additive/scalar } \\
\text { particle }\end{array}$ & X-mo & --- & X is & $\begin{array}{l}\text { NP dōu, or } \\
\text { dōu [vP ... }]\end{array}$ \\
\hline number is large & 10-CL-mo & --- & 10 NP is & $\begin{array}{l}10 \text { CL (NP) } \\
\text { dōu }\end{array}$ \\
\hline
\end{tabular}

\subsection{Theories and subtle interpretive differences}

Most of the literature pertaining to dou and mo concentrate on smaller subsets of the data. We briefly consider two accounts that strive to be relatively compre- 
hensive, Xiang (2008) and Kobuchi-Philip (2008, 2009, 2010). Xiang, building on Lin (1998) and Giannakidou \& Cheng (2006), places maximality in the center of her account of dou. In contrast, Kobuchi-Philip's starting point is the additive ('also') interpretation of mo. Clearly, the two approaches are quite different. We focus on how their basic intuitions correlate with the slight distributional and interpretive differences between the two particles.

6.2.1 Regarding mo, Kobuchi-Philip (2009) starts from examples such as the following:

(79) (gakusei-ga) John-mo hashitta

'(Among the students,) John also ran'

(gakusei-ga) [John-to Mary]-mo hashitta

'(Among the students,) John and Mary also ran'

(81) (gakusei-ga) John-mo Mary-mo hashitta

'(Among the students,) both John and Mary ran'

(82) (gakusei-ga) dono-hito-mo hashitta

'(Among the students,) every person ran'

Just like its English equivalent, sentence (79) requires for there to be a salient individual other than John who ran. This individual must be drawn from the set of students, if the subject gakusei-ga is present, or from a contextually given set if the sentence has a null subject. The same holds for (80); it requires for someone beyond John and Mary to have run. But (81) and (82) do not have a similar requirement. Sentence (81) is perfectly true and felicitous if no one besides John and Mary ran. Kobuchi-Philip's elegant proposal is that mo plays the same role in all these examples. The difference between (79) - (80) and (81) - (82) is due to the fact that in (81), where mo attaches both to John and to Mary, John's running satisfies the requirement posed by Mary-mo, and Mary's running satisfies the requirement posed by John-mo. Sentence (82) works analogously to (81), with the different elements in the set of students satisfying the "other runner" requirement for each other.

Kobuchi-Philip distinguishes quantificational mo, as above, from what she dubs the focus particle mo, and builds the scalar interpretations of the latter using focus and a likelihood-scale, similarly to the literature on English even.

6.2.2 Mo compared to mind vs. is. Prior to moving on to dou, let us recall that Hungarian covers the distribution of mo with two distinct elements: mind and is, 
as shown in table (78). Of these two, only mind forms universal quantifiers, and only is functions as an additive ('also') and scalar ('even') particle. They overlap in that both paired mind $A$ mind $B$ and paired $A$ is $B$ is express strictly distributive conjunction ('both' or 'as well as'). Just like Japanese mo, mind and is do not correspond to plain English and. Kobuchi-Philip's analysis of (79), (80), and (81) captures the intuition for non-scalar is very well. Given the overlap between the interpretations of $i s$ and mind, the analysis may be seen to extend to the universal quantifier mind(en).

\section{Kati is [Kati és Mari] is \\ Kati is (és) Mari is mind Kati mind Mari mind-en-ki}

Kati-mo
[Kati-to Mari]-mo

Kati-mo Mari-mo Kati-mo Mari-mo dono-hito-mo

\author{
'also/even Kate' \\ 'also/even Kate and \\ Mary' \\ 'Kate as well as Mary' \\ 'Kate as well as Mary' \\ 'everyone'
}

Yet, the fact that Hungarian uses two entirely distinct particles to cover these grounds gives us pause. The division of labor between mind vs. is gains significance from Shimoyama's (2006) suggestion that $m o$ as a universal and $m o$ as an additive particle are distinct. Shimoyama bases this on the fact that the intervention of the additive particle mo between quantificational mo and its target whword does not block the quantificational link.

One would also like to better understand the relation between the additive and the scalar versions of mo. Given that English too and also are not morphologically related to even, the two interpretations certainly can be built independently. But, as we learn from Gil (2008), it is cross-linguistically not unusual for the same particle to have both additive and scalar interpretations. Our preliminary suggestion here is the same as in 5.2. Mo, mind, and is are probably not singlehandedly responsible for all the semantic action in the examples at hand. It is more likely that they are aided by either type-shifters or phonetically null elements. The differences in their distribution are likely to follow from what silent helpers they team up with.

6.2.3 A comprehensive proposal for dou. Given that the key element of KobuchiPhilip's analysis is the additive use of $m o$, it is important to recall that although Cantonese has additive dou, Mandarin does not. We do not know whether the gap in Mandarin is due to the blocking effect of ye 'also, even' or, conversely, dou spills over to fill a vacant spot in the absence of ye in Cantonese. For the time being we regard the Mandarin situation as representative. Furthermore, both Mandarin and Cantonese dou lack the "conjunction" function exemplified in (77). Therefore, if the above analysis of mo is on the right track, then dou's 
overall profile, however similar it may be to that of $m o$, must be built on a different foundation.

Indeed, Xiang (2008) approaches dou quite differently. The key element of her account is maximality, following Giannakidou and Cheng (2006). She proposes that $d o u$ "gives rise to different meanings by applying maximality to a contextually determined plural set. This could be a set of covers, a set of focusinduced alternatives, or a set of degrees ordered on a scale [with the aid of lian]" (Xiang 2008: 227).

A subtle interpretive difference between dou on the one hand and even and mo on the other pertains to how unlikely an alternative has to be to satisfy the particles' scalar requirements. Although Xiang (2008: 230) says that even and (lian) ... dou are alike in requiring the most unlikely alternative to be true, it appears that neither even nor mo is that demanding: they are satisfied with an alternative that falls within the unlikely range but is not the most unlikely. To fix the contextual alternatives, imagine an old lady who is not used to eating anything but meat and potatoes. She is invited to a buffet dinner that offers, among many other things, plain rice, asparagus soufflé, and exotic seafood. Someone says,

(84) [The old lady enjoyed the dinner! She even tried the ...

(85) (kanojo-wa) ...-mo tabe-ta

(she-TOP) ...-MO eat-PAST

'She even ate/tried the...'

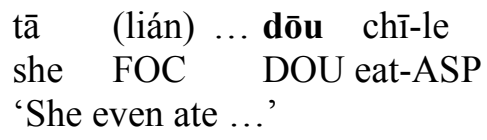

What "..." did the old lady have to eat to make these claims true and felicitous? For even and mo, it suffices if she tries the asparagus soufflé, which is already very unusual for her, whereas for dou, she has to try exotic seafood. This is in line with Xiang's claim that maximality is a crucial component in the interpretation of $\mathrm{dou}^{14}$

Xiang relates the distributivity properties of dou to its being a maximality operator:

\footnotetext{
${ }^{14}$ On the other hand, in none of the three languages does it seem to be required for the old lady to have tried all the dishes that are more likely than the one named, contrary to claims by both Xiang and Kobuchi-Philip. When one property logically entails another, e.g. eat at least five apples entails eat at least four apples, then this follows automatically; but it is not required in the absence of a logical entailment.
} 
"(16) Tamen dou mai-le fangzi

they dou buy-Perf house

a. 'They each bought a house/houses'

b. 'They bought houses'

This sentence couldn't mean that all the people bought a house together. In other words, there has to be some kind of distributivity involved. But it is ambiguous as to how to distribute the house-buying event. It could have a strong distributive reading such that each individual bought houses separately, as shown in (16a). But it could also mean something vague like (16b). Essentially (16) only says that each individual participated in some house-buying event, but we don't know who bought a house by himself, and who bought a house/houses with other people collectively. ... This flexibility makes the generalized distributor analysis very attractive (Lin 1998). The original motivation of using generalized distributors (Schwarzschild 1996) is exactly to account for the vagueness problem in the interpretation of plurals. ... The concept of covers is needed in interpreting plural nouns. Dou, as a maximality operator, operates at the level of a set of covers and outputs a maximal plural individual that consists of all the covers.... [T] his ensures that every individual in the set is included. I will also suggest that being a maximality operator, dou has a plural presupposition, such that the domain on which it operates has to contain more than one cover. It is this presupposition that in general rules out the single-cover reading."

(Xiang 2008: $232-237$ )

\subsection{The methodological questions raised by mo and dou}

Mo vis-à-vis dou raise a strategic question. We have seen one proposal for each that is basically successful in accounting for a range of properties exhibited by the given particle. The two proposals have different key elements (additivity vs. maximality), and that does not seem arbitrary: it correlates with certain differences in both distribution and interpretation.

So what is the status of the great similarities in the behavior of mo and dou? This is an important methodological question that will present itself again and again in studies of this sort, as discussed in Szabolcsi (2010: Ch 12.5).

(i) It is possible that the similarities are simply consequences of the semantic content that arises in two different and independent ways. Two expressions that are composed differently can perfectly well have the same meaning. It is an important advantage of having a model-theoretic semantics, in addition to logical form, that it makes it possible to prove such equivalences. 
(ii) On the other hand, the situation presented by mo vs. dou is reminiscent of question formation vs. topicalization in early generative grammar. Question formation and topicalization exhibit great similarities and also important differences. The response back then was to factor out the similarities in the shape of wh-movement, and to account for the differences with reference to other factors. One wonders whether the same approach could be applied here. If it is viable, then the two approaches can be evaluated with reference to which of them enables the mo and dou type data to fit into a bigger picture that also accommodates the $k a$ type data.

To wrap up, this section compared the distribution and interpretation of mo and $d o u$, in their roles as additive and scalar particles, connectives, components of free relatives, and universal/distributive quantifiers. The overall crosslinguistic comparison is a new contribution to the literature. We observed that from a bird's eye perspective mo and dou are extremely similar. How their compositional analyses should account for the similarities as well as the remaining differences is an important open question that we hope to take up in future work.

\section{Summary}

This paper pointed out a trend in recent research that questions the assumption that there is a dividing line between morphology and syntax, as well as the assumption that multi-morphemic units are simply lexicalized with idiosyncratic properties. The new view naturally leads to a notion of compositionality that operates on the smallest bits that sentences and words can be analyzed into and assumes that they contribute to meaning in a systematic fashion.

We highlighted a set of cases, especially pertaining to some particles that build quantifier words and also attach to phrases, which may serve to test and refine the new approach. We argued that it is plausible that their contribution is compositional. But many questions arise, due to gaps in the system and due to our currently incomplete understanding of how the exact range of meanings we find arise and relate to each other. We believe that these questions are productive ones and they should not scare us away. 


\section{References}

Abels, Klaus \& Luiza Martí 2011. Propositions or choice functions: What do quantifiers quantify over? http://ling.auf.net/lingBuzz/001376.

Alonso-Ovalle, Luis 2006. Disjunction in Alternative Semantics. PhD dissertation, UMass, Amherst.

Amritavalli, R. 2003. Question and negative polarity in the disjunction phrase. Syntax 6: 1-18.

A magyar nyelv történti-etimológiai szótára [Historical-Etymological Dictionary of the Hungarian Language], Vols. 1-3. 1967-1984. Budapest: Akadémiai Kiadó.

AnderBois, Scott 2012. Focus and uninformativity in (Yucatec Maya) questions. Natural Language Semantics 20:349-390.

Barwise, Jon \& Robin Cooper 1981. Generalized quantifiers and natural language. Linguistics and Philosophy 4: 159-219.

Beghelli, Filippo \& Timothy Stowell 1997. Distributivity and negation: The syntax of EACH and EVERY. In Szabolcsi, ed., Ways of Scope Taking. pp. 349-409. Dordrecht: Kluwer.

Bobaljik, Jonathan 2012. Universals in Comparative Morphology. Cambridge: The MIT Press.

Borzdyko, Oxana 2004. La disjonction, l'indéfinition et l'interrogation: la particule $C I$ du biélorusse. $\mathrm{PhD}$ disertation, University of Western Ontario.

Bumford, Dylan, James Doh Whang \& Vera Zu 2011. Composing quantifiers in Chinese and Japanese. Ms. New York University.

Cable, Seth 2010. The Grammar of Q. Q-particles, Wh-Movement, and PiedPiping. Oxford: OUP.

Ciardelli, Ivano, Jeroen Groenendijk \& Floris Roelofsen (2012). Inquisitive Semantics. NASSLLI 2012 Lecture Notes.

https://sites.google.com/site/inquisitivesemantics/courses/nasslli-2012.

Crain, Stephen \& Rosalind Thornton 2006. Acquisition of syntax and semantics.

In: Traxler \& Gernsbacher, eds., Handbook of Psycholinguistics, 2nd Edition. Oxford: Blackwell. 1073-1111.

Csirmaz, Aniko \& Anna Szabolcsi 2012. Quantification in Hungarian. In: Keenan \& Paperno, eds., Handbook of Quantifiers in Natural Language. Dordrecht: Springer. 399-467.

Enç, Mürvet 1991. The semantics of specificity. Linguistic Inquiry 22: 1-25.

Gärtner, Hans-Martin \& Beáta Gyuris 2007. Interpreting VAJON. http://ny01.nytud.hu/ gyuris/vajon-pres6-final.pdf.

Giannakidou, Anastasia \& Lisa Lai-Shen Cheng 2006. (In)Definiteness, polarity, and the role of wh-morphology in free choice. Journal of Semantics 23: $135-183$. 
Gil, David 1995. Universal quantifiers and distributivity. In: Bach, Jelinek, Kratzer \& Partee, eds., Quantification in Natural Languages, Dordrecht: Kluwer, 321-363.

Gil, David 2008. Conjunctions and universal quantifiers. In The World Atlas of Language Structures Online. http://wals.info/feature/description/56.

Goro, Takuya and Sachie Akiba 2004. The acquisition of disjunction and positive polarity in Japanese. In: Chand et al., eds., Proceedings of the 23rd West Coast Conference on Formal Linguistics. Somerville, MA: Cascadilla Press, 251-264.

Groenendijk, Jeroen \& Floris Roelofsen 2009. Inquisitive Semantics and Pragmatics. Language, Communication and Rational Agency, Stanford, USA, May 30-31, 2009.

Hackl, Martin 2009. On the grammar and processing of proportional quantifiers. MOST versus MORE THAN HALF. Natural Language Semantics 17: 63-98.

Hagstrom, Paul 1998. Decomposing Questions. PhD Dissertation, MIT.

Halle, Morris \& Alec Marantz 1994. Some key features of Distributed Morphology. In: MIT WPL 21: 275-288.

Hamblin, C. L. 1958. Questions. Australasian Journal of Philosophy 36:159168.

Hamblin, C. L. 1973. Questions in Montague English. Foundations of Language 10: 41-53.

Harley, Heidi 2012. Semantics in Distributed Morphology. In: Maienborn, von Heusinger \& Portner, eds., An International Handbook of Natural Language Meaning 2151-2172. Berlin: Mouton-de Gruyter.

Haspelmath, Martin 1997. Indefinite Pronouns. Oxford: Clarendon Press.

Heim, Irene 1985. Notes on comparatives and related matters. http://semanticsarchive.net/.

Heim, Irene 1999. Notes on superlatives. http://semanticsarchive.net/.

Huang, Shizhe. 1996. Quantification and predication in Mandarin Chinese: A case study of DOU. PhD Dissertation, University of Pennsylvania.

Hunyadi, László 1987. On the interpretation of the Hungarian quantifiers mind "every" and akár "any". Acta Linguistic Hungarica 37: 125-136.

Inquisitive Semantics Home, http://sites.google.com/site/inquisitivesemantics/.

Jacobson, Pauline 2002. The (dis)organization of grammar. Linguistics and Philosophy 25: 601-626.

Jayaseelan, K.A. 2001. Questions and question-word incorporating quantifiers in Malayalam. Syntax 4: 63-83.

Jayaseelan, K.A. 2011. Comparative morphology of quantifiers. Lingua 121: 269-286.

Julien, Marit 2002. Syntactic Heads and Word Formation. New York: OUP. 
Keenan, Edward \& Leonard Faltz 1986. Boolean Semantics for Natural Language. Dordrecht: Reidel.

Karttunen, Lauri 1977. The syntax and semantics of questions. Linguistics and Philosophy 1: 1-44.

Kayne, Richard 2005. Movement and Silence. Oxford: OUP.

Kayne, Richard 2010. Comparisons and Contrasts. Oxford: OUP.

Kiss, Katalin É. 2002. The Syntax of Hungarian. Cambridge: CUP.

Kobuchi-Philip, Mana 2008. Presuppositional compositionality with Japanese MO. Proceedings of Semantics and Linguistic Theory 18. Available at http://elanguage.net/journals/salt/article/view/18.496.

Kobuchi-Philip, Mana 2009. Japanese MO: universal, additive and NPI. Journal of Cognitive Science 10: 172-194. http://semanticsarchive.net/Archive/mIxZDk0N/.

Kobuchi-Philip, Mana 2010. Indeterminate numeral quantifiers, 'some' and 'many' readings, and questions in Japanese. Korean Journal of Linguistics 35: 503-530. http://semanticsarchive.net/Archive/TcxMWFlZ/.

Koopman, Hilda 2005. Korean (and Japanese) morphology from a syntactic perspective, Linguistic Inquiry 36: 601-633.

Koopman, Hilda \& Anna Szabolcsi 2000. Verbal Complexes. Cambridge: The MIT Press.

Kratzer, Angelika \& Junko Shimoyama 2002. Indeterminate pronouns: the view from Japanese. Proceedings of Third Tokyo Conference in Psycholinguistics and http://semanticsarchive.net/.

Landman, Fred 1991. Structures for Semantics. Dordrecht: Kluwer.

Leu, Thomas 2009. The Internal Syntax of Determiners. PhD dissertation, New York University.

Leu, Thomas 2010. The internal syntax of jeder 'every'. Linguistic Variation Yearbook 2009, pp. 153-204.

Lin, Jo-wang 1998. Distributivity in Chinese and its implications. Natural Language Semantics 6: 201-243.

Mascarenhas, Salvador 2009. Inquisitive Semantics and Logic. Master's Thesis, University of Amsterdam.

Nishigauchi, Taisuke 1990. Quantification in the Theory of Grammar. Dordrecht: Kluwer.

Paul, Ileana 2005. OR, WH- and NOT: free choice and polarity in Malagasy. In: Jeffrey Heinz \& Dimitrios Ntelitheos, eds., UCLA WPL 12: 359-367.

Ramchand, Gillian 1997. Questions, polarity, and alternative semantics. In Kusumoto, ed., Proceedings of NELS 27, 383-396. UMass, Amherst: GLSA.

Reichenbach, Hans 1947. Elements of Symbolic Logic. New York: Free Press. 
Reinhart, Tanya 1997. Quantifier scope: how labor is divided between QR and choice functions. Linguistics and Philosophy 20: 335-397.

Roelofsen, Floris 2012. Algebraic foundations for the semantic treatment of inquisitive content. Ms. http://sites.google.com/site/inquisitivesemantics/.

Rooth, Mats 1985. Association with Focus. PhD dissertation. UMass, Amherst.

Rooth, Mats 1992. A theory of focus interpretation. Natural Language Semantics 1: 75-116.

Schlenker, Philippe 2008. Be articulate: A theory of presupposition projection. Theoretical Linguistics 34: 157-212.

Schwarzschild, Roger 1996. Pluralities. Dordrecht: Kluwer.

Shan, Chung-chieh 2002. Binding alongside Hamblin alternatives calls for variable-free semantics. Proceedings of Semantics and Linguistics Theory 14. Available at http://elanguage.net/journals/salt/article/view/14.289.

Shimoyama, Junko 2006. Indeterminate noun phrase quantification in Japanese. Natural Language Semantics 14: 139-173.

Sigurðsson, Halldór 2004. The syntax of person, tense, and speech features. Rivista di Linguistica 16: 219-251.

Slade, Benjamin 2011. Formal and Philological Inquiries Into the Nature of Interrogatives, Indefinites, Disjunction, and Focus in Sinhala and Other Languages. PhD Dissertation, University of Illinois, Urbana Champaign. http://ling.auf.net/lingbuzz/001321.

Starke, Michal 2009. Nanosyntax: A short primer to a new approach to language. http://ling.auf.net/lingBuzz/001230.

Szabolcsi, Anna 1986. Comparative superlatives. MIT WPL 8, pp. 245-266 and http://semanticsarchive.net/.

Szabolcsi 1997a. Strategies for scope taking. In: Szabolcsi, ed., Ways of Scope Taking, pp. 109-154. Dordrecht: Kluwer.

Szabolcsi 1997b. Background notions in lattice theory and generalized quantifiers. In Szabolcsi, ed., Ways of Scope Taking, pp. 1-29. Dordrecht: Kluwer.

Szabolcsi, Anna 1997c. Quantifiers in pair-list readings. In Szabolcsi, ed., Ways of Scope Taking, pp. 311-349. Dordrecht: Kluwer.

Szabolcsi, Anna 2002. Hungarian disjunctions and positive polarity. In: Kenesei \& Siptár, eds., Approaches to Hungarian 8, pp. 217-241 and http://semanticsarchive.net/.

Szabolcsi, Anna 2010. Quantification. Cambridge: CUP.

Szabolcsi, Anna 2012. Compositionality without word boundaries: (the) more and (the) most. In: Chereches, ed., Proceedings of Semantics and Linguistic Theory 22, pp. 1-25. Available at http://elanguage.net/journals/salt/article/view/22.1. 
Tancredi, Chris 2004. Wh-mo NPs in Japanese: Quantifiers, plurals, or a different beast altogether? Talk handout, University of Maryland.

Xiang, Ming 2008. Plurality, maximality and scalar inferences: A case study of Mandarin DOU. Journal of East Asian Linguistics 17: 227-245.

Yatsushiro, Kazuko 2009. The distribution of quantificational suffixes in Japanese. Natural Language Semantics 17: 141-173.

Zimmermann, Malte 2009. Variation in the expression of universal quantification and free choice: The case of Hausa KOO-WH expressions. In Craenenbroeck, ed., Linguistic Variation Yearbook 2008, pp. 179-232. Amsterdam: John Benjamins. 